\title{
Permeability Damage and Supercritical Fluid Storage in the Cauvery Basin Neyveli Lignite Bed Containing Kaolinite Deposits during Alternative Injection of Brine and $\mathrm{CO} 2$
}

\author{
Perumal Rajkumar \\ Indian Institute of Science \\ Justine K. Antony \\ Annamalai University \\ Selvaraj Mahalingam \\ Sona College of Technology \\ Rakesh Ravi Shankar \\ University of North Dakota \\ Ramadoss Kesavakumar \\ DAWN CALORIFIC EXPORTS \\ Venkat Pranesh. R ( $\square$ petrovpr359@gmail.com ) \\ DAWN CALORIFIC EXPORTS
}

Case study

Keywords: Neyveli Lignite, Kaolinite, CO2, Brine, Permeability, Velocity

Posted Date: August 24th, 2020

DOI: https://doi.org/10.21203/rs.3.rs-61770/v1

License: (a) (i) This work is licensed under a Creative Commons Attribution 4.0 International License.

Read Full License 


\section{Abstract}

A laboratory based investigation has been conducted on permeability damage and $\mathrm{CO}_{2}$ storage or retention in the lignite core during alternative injection of brine and supercritical carbon dioxide. Moreover, anthracite and bituminous coal beds were focused by the scientific community for effective production and reservoir formation damage study. But, now-a-days, lignite based coal bed methane reservoirs have attracted attention for productive exploitation and formation collapse investigation. Hence, for this purpose, a single component injection two phase (Brine + Supercritical $\mathrm{CO}_{2}$ ) coreflood test analysis under alternative injections were performed to investigate the occurrence of lignite structural collapse, permeability damage, injectivity decline and $\mathrm{CO}_{2}$ retention as well. The experimental study reveals that, due to gravity segregation there is a high rate of fluid saturation in lignite core and also, moderate level of heat transfer coefficient was also noted. Also, lignite core structural collapse under the brine and supercritical $\mathrm{CO}_{2}$ injection at different velocities resulted in huge volume of coal and kaolinite fines concentration. Kaolinite and coal fines migration resulted in pressure change and permeability decline in lignite core. The suspensions produced were passed to microstructural analysis and it revealed that kaolinite fine particle tends to possess a leaflet geometrical structure, which obstructed the cleats and restricted the fluid flow. Subsequently, hysteresis modelling (Pranesh 2018) was applied to this problem to quantify the amount of $\mathrm{CO}_{2}$ retention in lignite core. Additionally, statistical model, multiple linear regression was applied to this problem to validate the experimental model, which showed good agreement.

\section{Introduction}

Coal bed methane (CBM) or coal mine methane (CMM) is a significant and unavoidable resource for natural gas exploration and production (Chen et al. 2020; Karacan and Warwick 2019; Zheng et al. 2018; Vedachalam et al. 2015; Moore 2012). Specifically, India has tremendous potential for the extraction of methane from coal beds (Rathi et al. 2019). Concurrently, the CBM reservoirs with clay mineral deposits are highly susceptible to reservoir formation damage due to fines (inorganic minerals) and coal fines (tiny fragment from broken coal matrix) migration under hydrodynamic and thermodynamic forces (Pranesh et al. 2019; Guo et al. 2018; Huang et al. 2018; Zhao et al. 2018; Zhao et al. 2016; Valentim et al. 2016; Han et al. 2015; Bai et al. 2015; Guo et al. 2015; Zeinijahromi et al. 2012; Seidle 2011). Actually, kaolinite clay minerals are located in several sedimentary formations, especially in sandstone and carboniferous rocks, and moreover, kaolinite occurs through dissolution of feldspar at extreme temperature and geochemical alterations (Mahalingam et al. 2019; Kanimozhi et al. 2019a). Figure 1 presents the kaolinite fines behaviour in lignite seam during the external fluid invasion. Typically, fines attached on the rock surface are under the influence of the four forces, namely, gravity, electrostatics, lift, and drag. Former two forces keep the fine particle over the rock surface and the latter two forces detach from the rock surface (Senthil et al. 2019; Zeinijahromi et al. 2016). Usually, fines have a size of order $1 \mu \mathrm{m}$ (Raha et al. 2007). Generally, a fine particle over a pore surface is held by a torque balance criterion, as mentioned by the below equation (Malgaresi et al. 2019; Yang et al. 2016; You et al. 2016): 
$\frac{\partial\left(\phi c+\sigma_{s}+\sigma_{a}\right)}{\partial t}+U \frac{\partial c}{\partial x}=0$

where, $\sigma_{s}+\sigma_{a}=$ Concentrations of attached and strained fines, $U=$ Darcy velocity, $c=$

Volumteric concentration of suspended particles, $t=$ time, $\phi=$ Porosity and, $x=$ Distance

Besides, fines tend to migrate during permeating fluid flow in porous rocks (Chequer and Bedrikovetsky 2019). The fines migration effects in lignite reservoirs is presented here. Pranesh et al. (2019), examined the kaolinite clay and coal fines production in Neyveli lignite core of Cauvery Basin, Southern India under ambient conditions. The authors conducted coreflood experiments to estimate the lignite structural collapse and permeability decline due to kaolinite and coal fines migration during water flooding under ambient conditions and different flow rate velocities. The kaolinite was identified to be a flake geometrical structure that has destructed the lignite cleats and declined the permeability and simultaneously, coal fines has also contributed to permeability damage during increasing flow rates of water flooding. Furthermore, there are also literature evidences that there is a significant amount of kaolinite clay mineral contents in lignite bed, especially in Greek lignite seams (Oikonomopoulos et al. 2013; Koukouzas 2007).

Guo et al. (2016), performed coreflood test and analytical modelling of permeability damage in bituminous coal caused by fines migration during water production. They reported that water flow in bituminous coal has induced the fines migration that has potentially damaged the coal permeability for about $35 \%$. Also, SEM-EDX revealed that the produced fines are $53 \%$ coal-mixture in which coal accounts for $35 \%$ and clay is $12 \%$. Mitchell and Leonardi (2016), made a micromechanical investigation of fines liberation and transport during coal seam dewatering. Initially, the authors stated that during dewatering stage the viscous stresses can cause the liberation and transport of clay fines in coal matrix. Their modelling outcomes suggest that clay fines are bound to colloidal forces, especially, electrostatic attraction and repulsion, and also, flow rate velocity in coal bed induces the fines migration and damages the permeability. Figure 2 shows the schematic diagram of fines behaviour over the rock surface under permeating fluid flow.

Tao et al. (2017), studied the fluid velocity sensitivity of coal reservoir and its effect on CBM well productivity of Baode Block, Northeastern Ordos Basin, China by conducting coreflood test. The authors reported that increasing rates of fluid flow velocity generates massive fines in coal matrix and subsequently, reduces the permeability of the coal bed. During single phase flow the fines generation intensity is larger, but during two phase gas-water flow, the coal fines desorption rate is rapid and the transport distance is short. Coalfields have good $\mathrm{CO}_{2}$ storage and diffusivity properties, which provides a method for effective and safe $\mathrm{CO}_{2}$ sequestration (Saghafi et al. 2007). Wong et al. (2010), analysed and reviewed the conceptual economics of full scale enhanced $\mathrm{CBM}$ production and $\mathrm{CO}_{2}$ storage in anthracite coals at South Qinshui basin, Shanxi, China. Actually, the authors used the field case data from this field 
for history matching with the reservoir model to estimate the viability and efficiency of the $\mathrm{CO}_{2}$ sequestration and their modelling produced good results. The high rank CBM reservoirs can retain high volumes of carbon dioxide with respect to increasing year. The $\mathrm{CO}_{2}$ retention in this particular formation is a function of increasing time.

Sampath et al. (2020), studied the supercritical- $\mathrm{CO}_{2}$ interaction time on the alterations in coal pore structure. The authors emphasized that carbon dioxide interaction time is an important parameter in geological sequestration of $\mathrm{CO}_{2}$ in coal seams and also changes the coal pore structure. Their modelling results revealed that this interaction time induce the coal to adsorb the $\mathrm{CO}_{2}$ effectively. Also, supercritical $\mathrm{CO}_{2}$ changes the pore morphology and enhances the coal swelling rate. Furthermore, Wdowin et al. (2014), analysed the determinable changes in the reservoir and cap rocks of the Chabowo Anticline caused by $\mathrm{CO}_{2}$-brine-rock interaction. The authors denote that $\mathrm{CO}_{2}$ with brine presence alter the physicochemical properties of reservoir and cap rock. Hence, the authors conducted an experimental investigation by taking samples of sandstone (reservoir rocks) and claystone (cap rocks) from Chabowo 1 and 3 boreholes, Chabowo Anticline, NW Poland and subsequently, analytical characterization were made. They mention that this structure could hold huge volumes of $\mathrm{CO}_{2}$. It was mainly found from their research outcomes that the $\mathrm{CO}_{2}$ brine interaction with reservoir rocks has contributed in corrosion and dissolution of mineral phases, especially precipitation of kaolinite crystals were observed. It is evident that $\mathrm{CO}_{2}$ brine in reservoir rocks would lead to geochemical based reservoir formation damage.

The present study employs $\mathrm{CO}_{2}$ brine injection fluids to study the transport and structural properties of the lignite seams under varying flow rate velocities. Furthermore, water alternating gas (WAG) is one of the efficient enhanced oil and gas recovery techniques in which water and gas are injected alternatively at regular intervals for better sweep efficiency and reduce gas channelling (Afzali et al. 2018). In this paper, we have employed brine and $\mathrm{CO}_{2}$ gas WAG injection fluid. The ultimate goal of this paper is to investigate the occurrence of reservoir formation damage that includes fines migration, permeability damage and structural collapse, and also supercritical carbon dioxide fluid storage in Neyveli lignite rock during alternative injection of brine and supercritical $\mathrm{CO}_{2}$.

\section{Geological Settings Of Neyveli Lignite Field}

The Neyveli lignite field is located exactly between $\mathrm{N}$ Latitude and $\mathrm{E}$ Longitude. The coal mine covers a distance of $44 \mathrm{~km}$ in N-S direction and $12 \mathrm{~km}$ in E-W direction. The lignite deposit is a part of the Cuddalore Formation of Late Miocene age and is associated with ferruginous and argillaceous sandstone and clay beds (Rao et al. 2009). Cauvery basin is a peri-cratonic rift basin in the south east India covering a sedimentary sequence ranging in age from the late Jurassic to recent. Also, the basin is bounded on the west by the exposures of the Precambrian South Indian Shield that resides unconformable beneath the sedimentary layers forming the basement to this basin (Mukherjee 2015a,b). 
Figure 3 shows the map of the Cauvery basin in SE India. Furthermore, Cauvery basin is a fault rift basin and holds significant reserves of oil and gas to a larger area (Mazumder et al. 2019). This basin almost encompasses $25000 \mathrm{~km}^{2}$ area and originated during the Late Jurassic to Early Cretaceous splitting of the Archean Indian basement and Australia-Antarctica plates (Dasgupta 2019; Veevers and Tewari 1995). Most importantly, Neyveli clay minerals are highly kaolinitic (Murthy et al. 1950) and contain 91.04\% of kaolinite deposits (Sinha and Guha 1990). Mainly, kaolinite in this formation can be used in metallurgical and foundry industries, because, kaolinite is highly refractory and it possesses excellent refractory properties and behaves as a standard refractory material (Sinha 1994).

Figure 4 shows the Neyveli lignite formation hydrogeological cross section. The hydrology of this formation are classified into three sections as: confined, semi-confined, and unconfined aquifer (Ramesh et al. 2019; NLC 2018; Chidambaram et al. 2012). The first section is attributed to the ground level up to a maximum depth of $50 \mathrm{~m}$ consisting of lateritic sand stones/alluvium, and water level fluctuates between ground level and $15 \mathrm{~m}$. The second section occurs top of the lignite seam in the Southern Parts of Mine. Its thickness varies between 5 and $10 \mathrm{~m}$ and exerts 3 to $5 \mathrm{kgf} / \mathrm{cm}^{2}$ minimal pressure. The occurrence of confined aquifer is predominant and its thickness is around $400 \mathrm{~m}$ in the core lignite region and pinches in the west. There is a continuous thick clay barrier within the lignite bearing strata at a depth close to 40 to $50 \mathrm{~m}$ that divides the aquifer into two parts such as Upper and Lower confined aquifer. This is mainly recharged due to rainfall in the $420 \mathrm{sq} \mathrm{km}$ of demarcated recharge, which is lying in the west of the lignite field. Overall, it exerts a 5 to $10 \mathrm{kgf} / \mathrm{cm}^{2}$ upward pressure at the lignite seam base. Figure 5 shows typical photograph of the Neyveli lignite rock.

Figure 6 shows the geological map of Neyveli lignite field showing three different mine areas. Tables 1 and 2 presents the Neyveli lignite rock analytical test data and geomechanical properties. Furthermore, samples from three mine areas were taken and examined for differential scanning calorimetry (DSC) and thermogravimetric analysis (TGA).

Table 1: Neyveli lignite rock analytical test data (Pranesh et al. 2019) 


\section{PROXIMATE ANALYSIS}

Typical analyses
Range in values
Range in TS-I Lab.

\begin{tabular}{llll} 
Moisture & $52.20 \%$ & $50-56$ & $49.83-51.78$ \\
\hline Ash & $2.60 \%$ & $2-5$ & $4.97-8.00$ \\
\hline Volatile Matter & $24.80 \%$ & $24-28$ & $23.18-23.8$ \\
\hline Fixed Carbon & $20.40 \%$ & $20-24$ & $18.97-19.49$ \\
\hline Gross calorific value Kg.cal/ kg & 2865 & $2600-2900$ & $2711-2791$ \\
\hline Net Calorific value Kg.cal/kg & & $2200-2400$ & $2308-2384$ \\
\hline Specific Heat of lignite 0.64 to 0.65 at 50\% Moisture level and 3\% Ash & \\
\hline 2. ULTIMATE ANALYSIS & & & \\
\hline Moisture & $10.40 \%$ & $10.0-14.0$ & $11.35-19.52$ \\
\hline Ash & $4.60 \%$ & $3.0-8.0$ & $1.93-5.66$ \\
\hline Carbon & $53.05 \%$ & $49.0-55.0$ & $47.24-57.45$ \\
\hline Hydrogen & $4.15 \%$ & $3.5-4.4$ & $3.66-4.31$ \\
\hline Nitrogen & $0.75 \%$ & $0.5-0.7$ & $0.04-0.71$ \\
\hline Sulphur & $0.80 \%$ & $0.9-1.3$ & $0.94-1.35$ \\
\hline Oxygen & $26.25 \%$ & $18.0-24.0$ & $20.04-25.74$
\end{tabular}

Hard groove grindability Index on air dried basis at 12\% - 13\% Moisture level 110-140

\section{CHEMICAL ANALYSIS OF LIGNITE ASH}

\begin{tabular}{llll}
\hline Silica as $\mathrm{SiO}_{2}$ & $16.20 \%$ & $10.0-20.0$ & $21.09-41.99$ \\
\hline Iron as $\mathrm{Fe}_{2} \mathrm{O}_{3}$ & $4.15 \%$ & $2.0-5.0$ & $8.67-17.50$ \\
\hline Aluminium as $\mathrm{Al}_{2} \mathrm{O}_{3}$ & $20.60 \%$ & $15.0-22.0$ & $7.46-18.51$ \\
\hline Titanium as $\mathrm{TiO}_{2}$ & & $0.5-1.0$ & \\
\hline Calcium as $\mathrm{CaO}$ & $26.70 \%$ & $23.0-33.0$ & $10.99-19.49$ \\
\hline Magnesium as $\mathrm{MgO}$ & $6.75 \%$ & $4.0-7.0$ & $3.00-8.16$ \\
\hline Sulphuric anhydrides $\mathrm{SO}_{3}$ & $25.60 \%$ & $25.0-35.0$ & $9.87-23.92$ \\
\hline Sodium $\mathrm{Na}_{2} \mathrm{O}$ & & $0.8-1.2$ & $0.93-1.49$ \\
\hline Potassium as $\mathrm{K}_{2} \mathrm{O}$ & & & $0.05-0.46$
\end{tabular}


4. FUSION CHARACTERISTICS OF LIGNITE

$\mathrm{ASH}$

Initial deformation point $\left({ }^{\circ} \mathrm{C}\right)$

$1080-1150$

Boiling Point $\left({ }^{\circ} \mathrm{C}\right)$

$1250-1320$

Flow point $\left({ }^{\circ} \mathrm{C}\right)$

$1320-1350$

Bulk density (g/cc)

1.1 to 1.2

Table 2: Geomechanical properties of Neyveli lignite rock

\begin{tabular}{|c|c|c|c|c|}
\hline \multirow{2}{*}{$\begin{array}{l}\text { Geomechanical } \\
\text { Properties }\end{array}$} & \multicolumn{4}{|c|}{ Litho Unites } \\
\hline & Lateritic & Varigated & Sandy Clay & Sandstone \\
\hline Water Content (\%) & $10-13$ & $5-13$ & $9-24$ & 32 \\
\hline Liquid Limit (\%) & $36-44$ & $36-50$ & $55-90$ & 14 \\
\hline Plastic Limit (\%) & $16-20$ & $16-22$ & $22-32$ & - \\
\hline Average Density $\left(\mathrm{kg} / \mathrm{m}^{3}\right)$ & 2.0 & $1.9-2.3$ & $2.0-2.3$ & $2.0-2.4$ \\
\hline Silt and Clay (\%) & $15-45$ & $45-70$ & - & $15-30$ \\
\hline Sand (\%) & $85-55$ & $55-30$ & - & 85.70 \\
\hline Cohesion (kg/ck²) & $6-9$ & $2.5-10$ & $2.0-9.0$ & $3.0-1.6$ \\
\hline $\begin{array}{l}\text { Compressive Strength } \\
\left(\mathrm{kg} / \mathrm{cm}^{2}\right)\end{array}$ & $12-18$ & $5.0-20$ & $4-20$ & $6-32$ \\
\hline $\begin{array}{l}\text { Angle of Internal } \\
\text { Friction (degrees) }\end{array}$ & $18-30$ & $15-35$ & - & $25-40$ \\
\hline $\begin{array}{l}\text { Coefficient of } \\
\text { Permeability (cm/sec) }\end{array}$ & $10^{-4}-10^{-5}$ & $10^{-5}-10^{-7}$ & - & $10^{-4}-10^{-6}$ \\
\hline Swell Factor (Dry) & 1.5 & $1.4-1.6$ & $1.5-1.6$ & $1.3-1.5$ \\
\hline Swell Factor (Wet) & 2.0 & $2.0-2.2$ & $2.2-2.4$ & $1.7-2.1$ \\
\hline
\end{tabular}


Figure 7 shows the DSC profile of Neyveli lignite rocks. It can be seen from the figure that three different samples exhibited different peaks. The samples 1 and 2 peaks were observed at $200^{\circ} \mathrm{C}$ and $250^{\circ} \mathrm{C}$ was noted for mine 3 lignite sample. The subsequent, heat flow rate was measured to be $7 \mathrm{js}^{-1} / \mathrm{g}, 11.3 \mathrm{js}^{-1} / \mathrm{g}$, and $14 \mathrm{js}^{-1} / \mathrm{g}$ respectively. It can be clearly seen from the figure that the mine 3 sample needs extra energy to elevate the temperature of the lignite, because, the peak value was observed at $250^{\circ} \mathrm{C}$. Also, it is implicated that the third sample from the mine 3 might be in the pilot stage or immature (NLC 2018). Actually, the mine 3 was under development and pilot stage. These peaks indicate the possibility of phase transition and also known as enthalpy transition. Since the peaks are positive (upward direction) and therefore, there might be a tremendous amount of heat release at those temperatures and the reactions are exothermic. The enthalpy transition of these lignite samples can be calculated by using the following equation:

$$
\Delta H=K A
$$

Where,

$$
\begin{aligned}
& \Delta H=\text { Transition enthalpy } \\
& K=\text { Calorimetri constant } \\
& A=\text { Curve Area }
\end{aligned}
$$

Figure 8 shows the Neyveli lignite rock TMA profile. It can be seen from the figure that there is a clear indication of peaks at $150^{\circ} \mathrm{C}$ that were exhibited by all three lignite samples. Initially, from $0^{\circ} \mathrm{C}$ to $100^{\circ} \mathrm{C}$ temperatures the elastic modulus was observed to be normal, but just after $100^{\circ} \mathrm{C}$, it showed an exponential growth in the elastic modulus and peaked at $150^{\circ} \mathrm{C}$. The lignite samples elastic modulus values was found to be $225 \mathrm{MPa}, 258 \mathrm{MPa}$, and $283 \mathrm{MPa}$. The peaks region is the elastic region, where the Neyveli lignite stiffness is under the state of equilibrium. For example, the lignite sample 1 elastic region is at $150^{\circ} \mathrm{C}$ with $225 \mathrm{MPa}$, whereas, a sample 3 elastic region is at $150^{\circ} \mathrm{C}$ with $283 \mathrm{MPa}$. Therefore, the temperature effects on lignite can significantly change the material physical properties.

\section{Materials And Methods \\ 3.1 Sample Preparation}

Figure 9a) shows the typical kaolinite clay under 200 mesh size and 9 b) shows the microstructural image of kaolinite fines under $400 \mathrm{~nm}$ magnification (Kanimozhi et al. 2020). In addition, Fig. 10a) shows the photograph of brine kaolinite colloidal solution and $10 \mathrm{~b}$ ) shows the mechanism of cations exchange between clay minerals and sand grain (McPhee et al. 2015). Actually, lignite rock was procured from Neyveli lignite mine and simulated that is moulded to a cylindrical lignite core. 
The readers may have a concern about the usage of moulded coal in this work than a raw coal with virgin coal structure. Readers could argue that raw coal core analysis yield good results and reliability instead of using simulate moulded coal core, because, there is a great difference in fracture structure of the moulded coal and the raw coal. This will have a great impact on the experimental measurement outcome. The explanation for using moulded coal than raw virgin coal is mentioned below:

- A raw coal can be extracted in a typical CBM reservoir through core-drilling method. Usually, CBM reservoirs located few meters from the surface and the gas is trapped in the cleat spaces of the coal bed. Generally, a well is drilled for extraction and production. A raw core can be extracted by the above method for laboratory based analysis. The possibility of kaolinite clay and coal fines migration during alternative injection of brine and supercritical $\mathrm{CO}_{2}$ by lab-scale investigation has been presented here. We have focused our case on the Neyveli Lignite Field at Cauvery Basin, Southern India. This is not a typical CBM field, but it is a mine, where lignite is extracted through open cast mining.

- As can be seen from the Fig. 4, hydrological cross section, that coal seam bed in the interface between clay and aquifer is located in deep layer. The well is not yet drilled to extract gas from this layer and presence of methane is proved in the layer. Therefore, it is difficult and almost impossible to extract the raw coal from the reservoir at this current time.

- So lignite samples were taken from the shallow open cast mined regions, as the one showed in the Fig. 5. Also, there were several outcrops of lignite seam at Neyevli Lignite Mines. Samples were crushed and pulverized to mould it as a cylindrical coal for lab based analysis. Additionally, this is a lab scale simulation to quantify the structural collapse, coal and kaolinite fines production during hydrodynamic and thermodynamic forces. Moreover, there was not much difference between the raw and the moulded coal cores. Even the uncertainties were less and also, our experimental outcomes supported our methodology.

- For instance, Wang et al. (2018), studied the water influence invasion on methane adsorption behaviour in coal. The authors have procured the coal samples from the Chinese coal mines and moulded it for lab-scale examination. The authors analyzed the water imbibition test in the moulded coal only and also, they have mentioned that "It is worth noting that moulded coal is used in this work instead of coal core for several reasons". Also, recently, coal packs (coal powder) were employed to study the relative permeability in coal bed methane reservoirs (Ge et al. 2019). Figure 11 shows the research methodology flow chart.

After obtaining samples from the mines, the lignite was pulverized to a fine powder in the 200 mesh range. Then, pulverized lignite and kaolinite clay powders were mixed in the proportion $55 \mathrm{wt} \%$ and $45 \mathrm{wt} \%$ in the Hamilton Beach mixer at $300 \mathrm{rpm}$. Subsequently, the mixture was sent to the moulding process for acquiring the cylindrical core. This process was performed and monitored in a careful manner since the nature of the product should not be altered. Cylindrical pattern of length $30 \mathrm{~cm}$ and diameter $10 \mathrm{~cm}$ was used for moulding. The mixture is fed into the pattern and it is heated at $40{ }^{\circ} \mathrm{C}$ in an industrial 
oven. Extreme temperature and time will make the mixture rigid and this will be against the true nature of lignite and coal.

Therefore, $40^{\circ} \mathrm{C}$ is maintained for about $15 \mathrm{~min}$ in order to obtain a brittle lignite core saturated with kaolinite clay. On the whole, a lignite core of $10 \mathrm{~cm}$ diameter and $20 \mathrm{~cm}$ length was simulated and the core is dried for $48 \mathrm{~h}$. Next, the core is sent to ultrasonic treatment at $5 \mathrm{MHz}$ for about $20 \mathrm{~s}$ and fractures appeared in several sections of the core and we assume that kaolinite particles were trapped in between the cleats. Overall, three cylindrical cores were used for coreflood test by using brine and supercritical $\mathrm{CO}_{2}$ injection fluids. It was observed that the hardness (in Rockwell Scale) of the acquired lignite mine sample is measured to be $15 \mathrm{HRC}$ at $40^{\circ} \mathrm{C}$ for the indentation time of $10 \mathrm{~s}$. But, 11-14 HRC (Rockwell Hardness Scale) was measured for a simulated lignite cores with kaolinite clay saturation under those conditions.

\subsection{Experimental Setup}

Figure 12 shows a schematic diagram of the coreflood test setup. It can be seen from the figure that the prepared lignite core (rolled with thin rubber sleeves) is placed in a stainless steel core holder and in turn placed inside the oven. The oven is attached with a thermocouple and pressure transducer (for measuring the pressure difference across the core). Furthermore, one side of the core holder has provisions for pneumatic piston pump (for pressure exertion) and suspension flow. On the same side, brine tank connected with the pump and $\mathrm{CO}_{2}$ cylinder is attached and overall these components are connected to the core oven system. Other side of the core oven apparatus has the provision (exit line) for effluent tank (for collecting the suspension-colloids). The flow lines are provided with ball valves and the whole coreoven thermal system is connected to the data acquisition system and subsequently, connected to the computer.

\subsection{Experimental Procedure}

The procedure for coreflood test is provided below:

1. Firstly, brine and supercritical $\mathrm{CO}_{2}$ gas of $25 \mathrm{~kg}$ mass were injected with the flow rate of $2.5 \mathrm{~cm} / \mathrm{s}$ in the lignite core under alternative periods (WAG injection). Subsequently, the mobilized kaolinite-coal fines and gas-brine suspension is collected in the effluent collector tank. It should be noted that the reservoir temperature is at $35^{\circ} \mathrm{C}$ and the $\mathrm{CO}_{2}$ will never undergo a supercritical state under this ambient condition. Therefore, $\mathrm{CO}_{2}$ is preheated to $180^{\circ} \mathrm{C}$ in order to convert this gas in subcritical state to a state of supercritical fluid. Then the supercritical $\mathrm{CO}_{2}(\mathrm{Sc}-\mathrm{C})$ was passed to the lignite rock core through WAG (brine alternative Sc-C that is one after another) process.

2. The same procedure is repeated for the other two sets of flow rate velocity $(3.5 \mathrm{~cm} / \mathrm{s}$ and $4.5 \mathrm{~cm} / \mathrm{s})$ by brine and supercritical $\mathrm{CO}_{2}$ under WAG injection.

3. Then, samples in the effluent were dried and sent to microstructural test for analyzing the kaolinite fine particle structure and mechanism that has plausibly obstructed the lignite cleats and damaged the permeability of the lignite rock core. 
4. Hysteresis modelling was applied to this coreflood test results for $\mathrm{CO}_{2}$ retention quantification.

5. Furthermore, experimental model was tested against the statistical model, multiple linear regression for model validation.

\section{Results And Discussions}

Three sets of coreflood test (brine $+\mathrm{Sc}-\mathrm{C}$ at $2.5 \mathrm{~cm} / \mathrm{s}, 3.5 \mathrm{~cm} / \mathrm{s}$, and $4.5 \mathrm{~cm} / \mathrm{s}$ ) have been conducted alternatively (one after another) and only average values of brine and Sc-C are shown in the plots.

\subsection{Fluid Saturation and Heat Transfer Coefficient}

Figure 13 shows the brine and supercritical carbon dioxide saturation variation with respect to increasing time. It can be seen from this figure that the fluid saturation gradually increases with time. The fluid injection was executed alternatively and first, brine has been injected in the lignite core and followed by supercritical $\mathrm{CO}_{2}$. Due to density difference, the Sc-C overtakes the brine in achieving maximum saturation in the lignite rock. It is evident from the Fig. 13 that the performance of supercritical $\mathrm{CO}_{2}$ is better than brine. Increasing saturation rate is the menace to the coal permeability, because, there is a generation of effective stress coefficient under different water saturations (Zhang et al. 2019a). Moreover, high pressure and high temperature in the reservoir causes $\mathrm{CO}_{2}$ to saturate with the water and eventually, dissolve in it and thereby, acting as a carbonated water in the reservoir (Mahdavi and James 2020). Subsequently, this triggers coal swelling and increases the strain rate that ultimately change or damage the permeability of the coal formation (Kiyama et al. 2011). Therefore, it should be noted that increasing level of $\mathrm{CO}_{2}$ and water saturations in the coal matrix will alter the mechanical properties of the coal (Zhang et al. 2019a; Sampath et al. 2019). The schematic diagram of gravity segregation in single lignite rock matrix is provided in Fig. 14, which shows the underlying mechanism to explain the exact behaviour of brine and Sc-C saturation in the lignite rock core.

The lignite face cleat is saturated with brine and supercritical $\mathrm{CO}_{2}$. Due to density and phase difference, the brine is settled at the bottom and $\mathrm{CO}_{2}$ rises to the top. This was possible by a process called gravity segregation, in which during multiphase flow high density fluid gravitate to the pore surface and less density fluid rises to top of the pore wall. Furthermore, gravity segregation elevates the saturation level and volumetric capacity of the porous medium and overall, enhancing the viscosity of injected fluids and change the capillary pressure as well (Rabinovich et al. 2020; Cheng and Rabinovich 2020). Moreover, it is observed that some amount of this supercritical fluid was dissolved in brine and adsorbed by the lignite surface.

The heat transfer coefficient variation with respect to increasing fluid saturation is plotted in Fig. 15. It was reported that the quantification of heat transfer coefficient is crucial for mass and momentum transfer to take place in any porous systems (Teruel and Díaz 2013; Narasimhan 2013; Choi et al. 2011). Usually, there is a generation of high heat release in the porous media during multiphase flow by heat rejection from the pore surface to the interspace (Pranesh and Ravikumar 2018). In addition, there is a 
huge amount of entropy production in porous rocks (Kanimozhi et al. 2019b) due to fines surface detachment and pore-throat entrapment under elevated heat and fluid flow rates, and also, deteriorating electrostatic strength (You et al. 2016; Schembre and kovscek 2005). It can be seen from the Fig. 15 that there is a gradual rise in the heat transfer coefficient $(\mathrm{HTC})$ for increasing fluid saturation and at a certain point there is an exponential growth in the heat transfer coefficient in the lignite core and after that there is a slight stabilization of heat transfer rates. The heat transfer coefficient performance of Sc-C is better and higher than the brine, because, supercritical fluid produces heat transfer during transport and also, generates energy conversion in a thermal system (Zhang et al. 2020). Increasing HTC induces kaolinite clay fines to detach and migrate in the porous rocks (Kanimozhi et al. 2020). Moreover, increasing, depth, time, and temperature produces in-situ thermal stress in the coal formations and this has an impact on coal reservoir permeability and methane extraction (Wang et al. 2020; Zhao et al. 2019). There is also a possibility of new permeability and cleats generation by thermal fracturing due to coal-gas interactions (Teng et al. 2016). Thus, the necessity for HTC estimation and analysis has been established.

\subsection{Coal Fines Velocity and Fines Concentration}

This section presents the variation of coal fines velocity and kaolinite fines concentration with respect to increasing pore volume injection (PVI). Massive coal fines are produced due to external fluid invasion, usually, water through the coal formation excessive wear under critical flow conditions (Huang et al. 2017). It can be seen from the Fig. 16 that coal fines velocity increases with respect to PVI. Increase of brine injection and saturation in the lignite core elevated the production and velocity of coal fines. The performance of supercritical carbon dioxide in coal fines production is comparatively less than in brine. Table 3 shows the lignite core structural collapse and coal fines data. Hence, it should be noted that the coal fines production and velocity are mainly a function of fluid flow rate (Tao et al. 2017; Han et al. 2015). 
Table 3

Lignite core structural collapse and coal fines data

\begin{tabular}{|lllll|}
\hline $\begin{array}{l}\text { Injection Fluid } \\
\text { Type }\end{array}$ & $\begin{array}{l}\text { Temperature } \\
\left({ }^{\circ} \mathbf{C}\right)\end{array}$ & $\begin{array}{l}\text { Flow Rate } \\
\text { Velocity } \\
(\mathbf{c m} / \mathbf{s})\end{array}$ & $\begin{array}{l}\text { Structural Collapse } \\
\text { Time } \\
\mathbf{( s )}\end{array}$ & $\begin{array}{l}\text { Amount of Coal } \\
\text { Fines } \\
\mathbf{( g )}\end{array}$ \\
\hline Brine & 35 & 2.5 & 1700 & 204.62 \\
\hline Brine & 35 & 3.5 & 1900 & 358.17 \\
\hline Brine & 35 & 4.5 & 2100 & 446.85 \\
\hline $\mathrm{CO}_{2}$ & $18{ }^{*}$ & 2.5 & 1300 & 164.93 \\
\hline $\mathrm{CO}_{2}$ & $180 *$ & 3.5 & 2100 & 195.21 \\
\hline $\mathrm{CO}_{2}$ & $180^{*}$ & 4.5 & 2300 & 210.75 \\
\hline$*$ Injection Temperature & & & \\
\hline
\end{tabular}

Figure 17 shows the variation of kaolinite clay fines concentration with respect to increasing PVI. It can be seen from this figure that increasing pore volume injection increases the kaolinite fines concentration and after some time, the concentration of kaolinite fines tend to decrease. The decline in the fines concentration is attributed to permeability damage by kaolinite fines straining (Prempeh et al. 2020; Kanimozhi et al. 2019a; Russell et al. 2017) and structural collapse as well (Pranesh et al. 2019). The performance of brine is relatively higher than that of the supercritical carbon dioxide. Moreover, after the end of each coreflood test the kaolinite clay fines are collected in the effluent tank. This effluent was investigated by dynamic light scattering (DLS Technique) to acquire the quantitative data of clay mineral fines concentration (Kanimozhi et al. 2020). Furthermore, the physical properties of the produced suspensions is presented in Table 4.

The schematic diagram (Fig. 18) illustrating fracture generation, coal and kaolinite clay fines production under WAG injection in a single lignite rock matrix. It can be seen from this figure that alternative injection of brine and supercritical $\mathrm{CO}_{2}$ at different velocities yield new fracture and cleat spaces, due to the external fluid impact on the lignite rock formation and also, this impact produces coal fine particles, which was broken from the rock matrix as a tiny fragment. Coal fines along with kaolinite clay fines migrate and transport within the cleat spaces in the lignite core and at certain point the particles are strained in the cleats (Guo et al. 2018) and some particles will form a suspension in the brine and $\mathrm{CO}_{2}$ and transport freely in the lignite rock core and finally, exit in the effluent collector. Additionally, cyclic loading will trigger permeability damage and structural collapse as well in the coal mine bed (Fan and Liu 2019). Moreover, $\mathrm{CO}_{2}$ injection will alter the capillary pressure of the multiphase fluids and induce geochemical reactions (Seyyedi et al. 2020). 
Table 4

Physical properties of produced suspensions

\begin{tabular}{|c|c|c|c|c|c|c|}
\hline $\begin{array}{l}\text { Injection } \\
\text { Fluid } \\
\text { Type }\end{array}$ & $\begin{array}{l}\text { Fluid } \\
\text { Phase } \\
\text { State }\end{array}$ & $\begin{array}{l}\text { Temperature } \\
\left({ }^{\circ} \mathrm{C}\right)\end{array}$ & $\begin{array}{l}\text { Flow Rate } \\
\text { Velocity } \\
\text { (cm/s) }\end{array}$ & $\begin{array}{l}\text { Electrical } \\
\text { Conductivity } \\
(\mu \mathrm{S} / \mathrm{cm})\end{array}$ & $\begin{array}{l}\text { Thermal } \\
\text { Conductivity } \\
(\mathrm{W} / \mathrm{m}-\mathrm{K})\end{array}$ & $\begin{array}{l}\text { Zeta } \\
\text { Potential } \\
(\mathrm{mV})\end{array}$ \\
\hline Brine & L & 35 & 2.5 & 218 & 4.6 & +42 \\
\hline Brine & L & 35 & 3.5 & 234 & 5.5 & +5 \\
\hline Brine & L & 35 & 4.5 & 251 & 5.8 & +4 \\
\hline $\mathrm{CO}_{2}$ & Sc-C & $180^{*}$ & 2.5 & 148 & 3.9 & +30 \\
\hline $\mathrm{CO}_{2}$ & Sc-C & $180^{*}$ & 3.5 & 187 & 4.7 & +16 \\
\hline $\mathrm{CO}_{2}$ & Sc-C & $180^{*}$ & 4.5 & 203 & 5.2 & +2 \\
\hline
\end{tabular}

\subsection{Pressure Change and Permeability Decline}

The plot of variations of pressure and permeability with respect to increasing PVI and time (Fig. 19) indicates the pressure change for enhancing pore volume injection. Kanimozhi et al. (2020) have reported that pressure change and permeability decline are directly proportional. It can be seen from the Fig. 19 that from $2 \mathrm{PVI}$ to $10 \mathrm{PVI}$ the pressure linearly rises to $40 \mathrm{Psi}$ and $36 \mathrm{Psi}$ for brine and Sc-C respectively. After that the lignite core pressure under the brine and supercritical $\mathrm{CO}_{2}$ flow displayed a gradual decline. This deterioration in the lignite core pressure is exclusively due to coal and clay fines straining in the cleats and fractures and also, structural change of the lignite rock has contributed to this pressure change. Generally, fines straining, plugging, and internal cake formation in the porous rocks decrease the permeability and restrict the fluid movement, and also, pressure drop across the reservoir rocks is the first stage of evidence of fines intrusion and permeability decline (Yang et al. 2019; Russell and Bedrikovetsky 2018; Vaz et al. 2017; Sacramento et al. 2015; Bedrikovetsky et al. 2001). Mahalingam et al. (2019), and Kanimozhi et al. (2019a), have reported that the pressure curve in the Fig. 19 is a standard pattern during fines migration in the porous rocks under brine and $\mathrm{CO}_{2}$ flow. Recent reports suggest that pressure change during fines intrusion under $\mathrm{CO}_{2}$ injection contributes to higher decline in the reservoir rock pressure than any other external injection fluid (Othman et al. 2018b; De Silva et al. 2017). For example, Sokama-Neuyam (2017), examined the impacts of fines mobilization during $\mathrm{CO}_{2}$ injection in sandstone cores. The authors emphasized that $\mathrm{CO}_{2}$-brine-rock reactions can induce the fines mobilization in the porous sandstone core. $\mathrm{CO}_{2}$ injection in the rock potentially lifts the fines from the pore surface and migrate in the porous interspace and ultimately, plug the pore-channels, which finally leads to permeability deterioration. Importantly, petrophysical characteristics of the rock and hydrodynamic forces 
play a vital role in triggering this formation damage and in addition, mineral dissolution and salt precipitation also lead to this phenomenon under $\mathrm{CO}_{2}$ presence.

The permeability decline with respect to increasing time is shown in Fig. 20. It should be noted that water and $\mathrm{CO}_{2}$ injection in porous rocks lead to suspension transport and eventually, the particles being captured in the rock grain and contributing to permeability damage or decline, where the reservoir fluid transport is deteriorated and arduous or almost impossible for surface recovery (Kanimozhi et al. 2020; Mahalingam et al. 2019; Bedrikovetsky and Caruso 2014). It can be seen from this figure that there is a gradual decline in the lignite core permeability and permeability stabilization occurred in between the injection period. This permeability decrease was observed under both brine and supercritical $\mathrm{CO}_{2}$ transport, where the intensity of Sc-C is slighter higher than the high salinity water, in which long period of stabilization and decline was recorded. Furthermore, increasing flow rate velocity deteriorates the permeability by fines penetration and capture in the porous rocks (Guo et al. 2015; Oliveira et al. 2014). It was also reported that increasing level of $\mathrm{NaCl}$ concentration in the injected water and also, fresh water transport cause high retention of fines in the porous rocks and subsequently, contributing to reduction in the rock permeability (Yu et al. 2018). Furthermore, temperature and steady state flow effects on the fines migration in gas fields lead to rapid pore-plugging and permeability damage (Zeinijahromi et al. 2012), and also this phenomenon makes the gas wells to undergo an adiabatic state. (Senthil et al. 2019).

A schematic 2D isometric view of size exclusion mechanism between kaolinite clay fines and cleats in a lignite seam (Fig. 21) is presented exclusively for explaining the kaolinite fines straining in the lignite rock and coal fines analysis is neglected, because, of smaller size than kaolinite fine particle. Actually, kaolinite clay mineral fine particles liberate from the lignite surface and migrate in cleats under the brine and supercritical $\mathrm{CO}_{2}$ transport and this WAG injection makes the kaolinite clay fines to undergo a suspension and triggers suspension transport. During two phase flow of brine and $\mathrm{CO}_{2}$ there is capillary heterogeneity effects, which affect the geomechanical properties of rock (Rabinovich et al. 2015). Moreover, effective flow of reservoir fluids in the rock depends upon the pore size distribution and cleats network (Jin et al. 2019; Chalk et al. 2012). Also, colloidal-suspension transport produces high amount of fines retention and pore-straining that ultimately deteriorate the permeability of reservoir rock (Bedrikovetsky et al. 2017). It can be seen from the Fig. 21 that kaolinite fine particles are captured or strained in the cleat junction by a mechanism called size exclusion (Bedrikovetsky 2008). This mechanism states that differences in the particle and pore-throat area or cleat junction area cause straining and obstruct the permeability (You et al. 2014; Santos et al. 2008; Santos and Bedrikovetsky 2006). In this scenario, the kaolinite fine particle size is larger than the area of pore-throat or cleat junction, in which the kaolinite fines are strained in the cleat junctions. Thus, the fine particles are captured in porous, fracture, and cleat network rocks by size exclusion mechanism and consequently, damaging the permeability and decreasing the fluid recovery rate.

\subsection{Microstructural Examination}


After each coreflood test, the effluent containing colloidal samples were subjected to field emission scanning electron microscopic (FESEM) analysis. This is examined in order to identify the fine particle geometrical structure and investigate the plausible mechanism of permeability decline. Furthermore, Khilar and Fogler (1998), expressed that clay mineral fines morphology, shape, size, charge, structure and geometry can be characterized only by the microstructural analysis. Also, this assists to determine the permeability damage in the porous environments (Civan 2007). Figure 22a presents the FESEM images of brine produced suspensions at $2.5 \mathrm{~cm} / \mathrm{s}, 2 \mu \mathrm{m}$ (a), $3.5 \mathrm{~cm} / \mathrm{s}, 2 \mu \mathrm{m}$ (b), and $4.5 \mathrm{~cm} / \mathrm{s}, 2 \mu \mathrm{m}$ (c). It can be seen from the Fig. 22a that at these three flow rate conditions the kaolinite fine particles were identified to be a leaflet structure and there is also an appearance of the coal fines distribution. It has been revealed that kaolinite leaflets has impeded the Neyveli lignite rock core cleats by fines plugging and clogging. The kaolinite leaflet undergoes a clogging process during the formation of fines clusters under water invasion in the porous rocks (Chequer et al. 2019). There is also an observation of coal (lignite) swelling under these three flow rate velocities, which is indicated in orange squares. Moreover, coal swelling swiftly changes the material morphology and drastically reduces the permeability (Zhang et al. 2016).

Then, Fig. $22 \mathrm{~b}$ presents the FESEM images of supercritical $\mathrm{CO}_{2}(\mathrm{Sc}-\mathrm{C})$ produced suspensions at $2.5 \mathrm{~cm} / \mathrm{s}$, $1 \mu \mathrm{m}(\mathrm{e}), 3.5 \mathrm{~cm} / \mathrm{s}, 1 \mu \mathrm{m}(\mathrm{f})$, and $4.5 \mathrm{~cm} / \mathrm{s}, 3 \mu \mathrm{m}(\mathrm{g})$. It can be observed from these images that even in this case, the kaolinite was found to have a leaflet geometrical structure. Even there is a distribution of coal fines over rock and in this case also, the permeability was largely influenced and deteriorated by kaolinite leaflets by the mechanisms of plugging, clogging, and binding. There is also an observation of gas adsorption by kaolinite clay and rock and also, there is an appearance of lignite swelling and imbibition. Furthermore, $\mathrm{CO}_{2}$ injection in coal seams generates high ins-situ stress and high swelling rates, which ultimately decrease the permeability to a great extent, as this phenomenon was observed and reported in Kushiro low rank coals from Kushiro coal basin, Japan (Anggara et al. 2016). It should be noted that beyond brine injection, the $\mathrm{CO}_{2}$ injection and transport in porous rocks has savaging effects on fines migration and porous rock permeability (Mahalingam et al. 2019). For example, Xie et al. (2017) reported fines migration during $\mathrm{CO}_{2}$ injection through experimental investigation as a function of surface forces. The authors conducted a series of coreflood experiments to confirm the migration of fines that affects the permeability of the porous formation by considering total surface force. It was found that a reduction in the permeability of the porous formation was recorded during post flood operations. Even nuclear magnetic resonance spectroscopy (NMR) test confirms the migration of fines and later the analysis and revelation permeability reduction in the cores. Overall, the authors explicitly stated that kaolinite fines migration was the reason for instigating permeability deterioration during $\mathrm{CO}_{2}$ transport. Therefore, based on the Figs. 22a and 22b, the plausible mechanism of permeability damage and structural collapse was proposed in the Fig. 23. Actually, this Fig. 23 illustrating the plausible damaging mechanism of transport and geomechanical characteristics of the Neyevli lignite core due to the intrusion of kaolinite leaflets, coal fines, and $\mathrm{CO}_{2}$ retention under WAG (Brine $+\mathrm{Sc}-\mathrm{C}$ ) injection. In this microstructural investigation, emphasis is given to kaolinite fines than coal fines, because, its size distribution is very small roughly up to several microns. However, production of coal fines is strongly associated with the distribution of local flow velocity and coal cleat geometry (Bai et al. 2015). On the 
other hand, the kaolinite fines are bound to Derjaguin-Landau-Verwey-Overbeek (DLVO) interactions, which causes clay fines to form colloidal suspension and subsequent, permeability decline as well (Mitchell and Leonardi 2016).

Figure 24 shows the electrostatic attraction between the kaolinite clay fines and lignite rock under various forces. The total interaction force (TIF) was calculated based on the zeta potential and using DLVO theory, in which all forces exhibit forces of attraction and repulsion, shown in Fig. 24a). It should be noted that positive total interaction force means repulsive force and negative TIF means attractive force (Keshavarz et al. 2015). Figure 24b) presents the electrostatic interaction between the kaolinite clay fines and lignite rock under the brine and supercritical $\mathrm{CO}_{2}$ flow. It can be seen from the Fig. 24b) that both cases have undergone a positive (repulsion) and negative (attraction) TIF at different flow rate velocity conditions. Generally, under repulsion TIF the fines tend to migrate and barricade the coal cleats permeability (Keshavarz et al. 2014) and also, ionic strength, pH conditions of the lignite contribute to the permeability decline (Wang et al. 2019). High excitation level of positive TIF was produced during $\mathrm{CO}_{2}$ flow in the porous rock and this has severe impact on the rock permeability than any other liquid fluids (Xie et al. 2017). The kaolinite fines have undergone rock surface detachment, migration, and cleats entrapment during WAG flooding, which on the whole decline the lignite permeability.

\subsection{Injectivity Decline and $\mathrm{CO}_{2}$ Retention}

The variation of injected fluid recovery rate with respect to increasing time is provided in Fig. 25. It is evident from the previous sections that the lignite rock underwent a structural collapse and permeability impairment during WAG (Brine + Sc-C) injection at different velocities. Specifically, coal fines production and kaolinite leaflets have obstructed the cleats and nanopores of the lignite rocks and consequently, the permeability decreased sharply, which contributed to the overall injectivity decline. It was observed from the microstructural images that due to WAG injection the lignite has experienced swelling and imbibition, and also, $\mathrm{CO}_{2}$ retention occurred. It was reported that $\mathrm{CO}_{2}$ sorption and swelling can cause coal core structural change and damage (Pirzada et al. 2018). It can be seen from the Fig. 25 that initially the injected fluid recovery rate performance was linearly increasing for brine and Sc-C cases, in which the performance of brine is better than that of the supercritical $\mathrm{CO}_{2}$. After certain time, both cases exhibited a plummet in the produced fluid recovery rate and stabilized for increasing time. This sharp fall in the produced fluid recovery rate is due to structural collapse and coal fines production, and mainly, kaolinite clay fines migration. Furthermore, fines comprising porous rocks undergo a colloidal-suspension flows under external fluid injection, especially water flow and this causes fines to detach from the rock and finally migrate and entrap in the pore-throats and cleats areas of rock, where the damaging the permeability and declining the recovery of the injected fluid (Chequer et al. 2018; Russell et al. 2014; Guo et al. 2015; Kalantariasl et al. 2014). Moreover, reduction in the surface energy and pore-straining in the porous rocks gradually lead to injectivity decline (Kanimozhi et al. 2018; Gomes et al. 2017).

\subsubsection{Hysteresis Modelling of $\mathrm{CO}_{2}$ Retention in Lignite Rock}

Page 17/53 
Hysteresis modelling was implemented in the present investigation for estimating the percentage of $\mathrm{CO}_{2}$ retention in the lignite rock core. To the best of our knowledge, this is the first paper to apply hysteresis modelling to coal plug based coreflood experiments for $\mathrm{CO}_{2}$ retention percentage evaluation. This hysteresis modelling was carried out from our earlier work- Pranesh (2018). The hysteresis trapping of $\mathrm{CO}_{2}$ is a process in which the carbon dioxide phase is retarded from brine front, when the capillary pressure exerting on it has changed and it could be an alteration from the fluid viscosity and internal friction (Pranesh 2016). Moreover, $\mathrm{CO}_{2}$ trapping in between the pore spaces is the dominating factor in the hysteresis occurrence and also, there is a micro scale observation of advective process due to hysteresis induced capillary force (Narinesingh and Alexander 2014). Supercritical $\mathrm{CO}_{2}$ in the porous rocks are sequestrated and locked in pore and fractured spaces and consequently, trapped by hysteresis and dissolved in the formation water (Doster et al. 2013) and in this case, a certain amount of $\mathrm{CO}_{2}$ is dissolved in brine, which was already mentioned. Furthermore, brine has an excellent maganetohydrodynamic (MHD) properties and can easily attract other fluids to react (Babu and Ganesh 2018) and we assume that the brine has dissolved Sc-C due to this $\mathrm{MHD}$ effect. Brine- $\mathrm{CO}_{2}$ interactions during $\mathrm{CO}_{2}$ storage in deep coal seams lead to chemical precipitation and clay and inorganic mineral alterations (Wang et al. 2016). Also, the presence of kaolinite clay in the porous rocks can trap $\mathrm{CO}_{2}$ by mineral trapping mechanism (Mahalingam et al. 2019).

Table 5 presents the $\mathrm{CO}_{2}$ retention data in the lignite core during WAG injection and these data were obtained from the hysteresis modelling. It can be seen from the table that huge amount of carbon dioxide was trapped by hysteresis under constant injection pressure and injection rate (mass) during alternative injection of brine and Sc-C at each PVI. In general, under a brine-rock- $\mathrm{CO}_{2}$ reactions the $\mathrm{CO}_{2}$ storage in the porous rocks are based on mineral and rock surface areas (Kweon and Deo 2017). Furthermore, WAG transport and retention in porous media are dominated by capillary pressure and hysteresis effects (Afzali et al. 2020). The hysteresis phenomenon occurs naturally during WAG cycles during two phase flow in porous subsurface environments (Mahzari and Sohrabi 2017). Specifically, during $\mathrm{CO}_{2}$ transport cycle phase, this supercritical fluid is trapped and stored in the nano and mesopores of the coal formation (Du et al. 2020; Xu et al. 2019; Ming et al. 2017; Godec et al. 2013). In this case, the supercritical carbon dioxide has undergone a sequestration by three following processes through hysteresis effect:

- Sc-C retention and storage in lignite pores.

- Sc-C dissolved in the brine.

- Mineral trapping of Sc-C by kaolinite clay. 
Table 5

$\mathrm{CO}_{2}$ retention data in lignite core during WAG injection

\begin{tabular}{|llll|}
\hline PVI & Injection Pressure (Psi) & $\begin{array}{l}\text { Injection Rate } \\
(\mathbf{k g} / 3 \text { min) }\end{array}$ & $\begin{array}{l}\mathrm{CO}_{2} \text { Trapped by Hysteresis } \\
(\mathbf{k g})\end{array}$ \\
\hline 2 & 45 & 25 & 2.25 \\
\hline 4 & 45 & 25 & 3 \\
\hline 6 & 45 & 25 & 4.5 \\
\hline 8 & 45 & 25 & 5.5 \\
\hline 10 & 45 & 25 & 6.25 \\
\hline 12 & 45 & 25 & 7.25 \\
\hline 14 & 45 & 25 & 7.75 \\
\hline 16 & 45 & 25 & 8.5 \\
\hline 18 & 45 & 25 & 11.5 \\
\hline 20 & 45 & 25 & 13 \\
\hline
\end{tabular}

Figure 26 shows the variation of carbon dioxide retention percentage with respect to increasing pore volume injection. The $\mathrm{CO}_{2}$ retention percentage was calculated after obtaining hysteresis results of supercritical $\mathrm{CO}_{2}$ has been trapped in the lignite core. The percentage of this greenhouse gas retention was estimated by using the modified formula of Olea (2015):

Retention $\%=100 \times \frac{\mathrm{CO}_{2} \text { Remaing at the Rock Core Plug }}{\text { Cumulative } \mathrm{CO}_{2} \text { Injected }}$

During retention percentage calculation, it was assumed that the amount of carbon dioxide remaining at the Neyveli lignite core plug is equal to the amount of carbon dioxide trapped by the hysteresis. It can be seen from the figure 26 that the retention percentage of supercritical $\mathrm{CO}_{2}$ linearly increases for increasing pore volume injection. This rise in the $\mathrm{CO}_{2}$ retention in lignite core is absolutely due to the hysteresis effect during WAG cycle and a maximum of $53 \%$ of Sc-C has been retained in the lignite core plug. Soaking and solubility period of $\mathrm{CO}_{2}$ saturated with the liquid phase, eventually, miscible and trap in the reservoir (Lee et al. 2019; Pranesh et al. 2018; Mosavat and Torabi 2014). Supercritical $\mathrm{CO}_{2}$ flooding changes the rock geomechanical property and yield a high amount of storage (Zhang et al. 2019b; Zhang et al. 2017; Sander et al. 2014; Zunsheng et al. 2014). Therefore, hysteresis modelling was successfully applied to the Neyveli lignite rock during WAG injection and more than $50 \%$ of supercritical $\mathrm{CO}_{2}$ retention has been achieved. 


\subsection{Model Validation}

Figure 27 presents the model validation, which was plotted between pore volume injection and permeability decline (fig. 27a) and pore volume injection and $\mathrm{CO}_{2}$ retention percentage (fig.27b). The experimental data model was tested against the statistical model, multiple linear regression. Moreover, multiple regression is one kind of technique and most popular method that uses many variables to predict the response variable outcomes (George and Mallery 2016; Pandya et al. 2014). On the whole, the experimental data of these two variables in the figures 27 a) and b) separately fed in the statistical package for social science (SPSS) simulation tool to quantify the model performance and validity. Overall, the modelling revealed high agreement and this is obvious in figures 27 a) and b). It can be seen from these figures that both experimental and statistical model curves overlap, which indicates their performances are good and reliable. Generally, the curves overlap and merge indicate a good correlation between the testing and response variables (Pranesh et al. 2018). Therefore, both figures confirm that the lignite core permeability decline and high $\mathrm{CO}_{2}$ retention in the rock matrix were achieved under alternative injection of brine and supercritical carbon dioxide.

\section{Conclusions}

Lignite seam formations with kaolinite deposits are highly fragile in reservoir formation damage, especially structural collapse and permeability decline under hydrodynamic and thermodynamic forces. This phenomenon was successfully demonstrated using field case, Neyveli Lignite Formation at Cauvery Basin, SE India. A lignite sample was procured and simulated with kaolinite clay for coreflood test to examine permeability damage and supercritical fluid storage occurrence during alternative injection of brine and $\mathrm{CO}_{2}$. Therefore, based on the coreflood and analytical investigations following conclusions were drawn:

1. A linear increase and stabilization in injected fluid (Brine $+\mathrm{Sc}-\mathrm{C})$ was observed with respect to increasing injection time. This gradual increase in the two phase fluid saturation in lignite core was due to effective surface energies in the cleats and fractures of the lignite matrix and also, this has given rise to lignite swelling and imbibition. This high level of fluid saturation in lignite rock was possible by a mechanism of gravity segregation between Brine and Sc-C in cleats and fractures. Sluggish linear heat transfer coefficient rate in lignite core was recorded for increasing fluid saturation.

2. Structural collapse of lignite was observed under alternative injection of brine and supercritical $\mathrm{CO}_{2}$. This had led to coal fines production in the lignite core along with kaolinite fines, where the fines concentration has increased dramatically. But, after certain pore volume injection, the kaolinite fines tend to decrease gradually and this is mainly due to the domination (wt \%) of coal fines.

3. The rise and fall of lignite rock core pressure were observed and supercritical $\mathrm{CO}_{2}$ exhibited a linear decline than that of brine. This pressure loss is absolutely due to coal and kaolinite fines intrusion and straining in lignite cleats and also known as size exclusion mechanism. Consequently, the permeability of the lignite declined heavily with respect to increasing pore volume injection. However, 
it should be noted that certain level of permeability of the lignite core was deteriorated due to structural collapse.

4. Produced colloidal-suspensions in the effluent under FESEM analysis revealed that kaolinite fine particle has leaflet geometry and it has undergone plugging, clogging, and binding, which overall damaged the permeability of the lignite core and also, lignite swelling, imbibition, and gas adsorption was noted. Furthermore, electrostatic attraction and repulsion between kaolinite fines and lignite rock under brine and $\mathrm{Sc}-\mathrm{C}$ flow under the different velocities has validated the microstructural examinations and supported our arguments of permeability damage mechanism. Additionally, plausible mechanism was presented to indicate the permeability damage in lignite core due to the intrusion of kaolinite leaflets, coal fines, and $\mathrm{CO}_{2}$ retention under WAG transport.

5. Hysteresis modelling was applied to this scenario in order to estimate the $\mathrm{CO}_{2}$ retention percentage in lignite core. The hysteresis modelling was implemented in this problem based on the recommendations from our earlier publication- Pranesh (2018). The modelling outcomes revealed that huge quantity of $\mathrm{CO}_{2}$ has been trapped in the lignite rock by hysteresis. Also, linear increase in the $\mathrm{CO}_{2}$ retention was achieved with respect to increasing pore volume injection. Actually, more than $50 \%$ supercritical carbon dioxide retention was accomplished in the lignite core.

6. Furthermore, the experimental model was validated against the statistical model, multiple linear regression. Actually, two parameters, namely, permeability decline and $\mathrm{CO}_{2}$ retention percentage were taken for analysis, and both showed high agreement.

\section{Declarations}

\section{CONFLICT OF INTEREST:}

The authors declare no conflict of interest.

\section{Acknowledgement}

Mr. Sankara Narayanan, Chief General Manager at Neyveli Lignite Corporation, India is thanked for supplying the lignite samples and geomechanical data. Furthermore, Mr. Aaron Castro, Research Scholar at the Earth Sciences Department of Annamalai University, Chidambaram, TN, India is thanked for the assistance on Cauvery basin and Neyveli lignite map acquisition and also, Mr. Vivek Thamizhmani, Petroleum Consultant and Assistant Professor at VISTAS, Chennai, TN, India is acknowledged for the fruitful discussions on reservoir formation damage in CBM reservoirs.

\section{References}

Afzali, S, Ghamartale, A, Rezaei, N, and Zendehboudi, S, 2020, "Mathematical modelling and simulation of water-alternating-gas (WAG) process by incorporating capillary pressure and hysteresis effects", in, Fuel, 
vol. 263, pp 116362.

Afzali, S, Rezaei, N, and Zendehboudi, S, 2018, "A comprehensive review on enhanced oil recovery by water alternating gas (WAG) injection", in, Fuel, vol. 227, pp. 218-246.

Anggara, F, Sasaki, K, and Sugai, Y, 2016, "The correlation between coal swelling and permeability during $\mathrm{CO}_{2}$ sequestration: A case study using Kushiro low rank coals", in, International Journal of Coal Geology, vol. 166, pp. 62-70.

Babu, R, D, and Ganesh, S, 2018, "The mathematical model for steady magnetohydrodynamic flow between parallel porous plates with an angular velocity", in, International Journal of Ambient Energy, pp. $1-9$.

Bedrikovetsky, P, 2008, "Upscaling of stochastic micro model for suspension transport in porous media", in, Transport in Porous Media, vol. 75, pp. 335-369.

Bedrikovetsky, P, You, Z, Badalyan, A, Osipov, Y, and Kuzmina, L, 2017, "Analytical model for strainingdominant large-retention depth filtration", in, Chemical Engineering Journal, vol. 330, 1148-1159.

Bedrikovetsky, P, and Caruso, N, 2014, "Analytical model for fines migration during water injection", in, Transport in Porous Media, vol. 101, pp. 161-189.

Bedrikovetsky, P, Zeinijahromi, A, Siqueira, F, D, Furtado, C, A, and de Souza, A. L. S, 2012, "Particle detachment under velocity alteration during suspension transport in porous media", in, Transport in Porous Media, vol. 91, pp. 173-197.

Bedrikovetsky, P, Siqueira, F, Furtado, C, and Souza, A, 2011, "Modified particle detachment model for colloidal transport in porous media", in, Transport in Porous Media, vol.86, pp. 353-383. 
Bedrikovetsky, P, Marchesin, D, Shecaira, F, Souza, A, L, Milanez, P, V, and Rezende, E, 2001, "Characterization of deep bed filtration system from laboratory pressure drop measurements", in, Journal of Petroleum Science and Engineering, vol. 32, pp. 167-177.

Chalk, P, Gooding, N, Hutten, S, You, Z, and Bedrikovetsky, P, 2012, "Pore size distribution from challenge coreflood testing by colloidal flow", in, Chemical Engineering Research and Design, vol. 90, pp. 63-77.

Chen, W, Guo, X, Zou, E, Luo, M, Chen, M, Yang, M, Li, H, Jia, C, Deng, C, Sun, C, Liu, B, Yang, L, and Chen, G, 2020, "A continuous and high-efficiency process to separate coal bed methane with porous ZIF-8 slurry: Experimental study and mathematical modelling", in, Green Energy \& Environment.

Cheng, K, B, and Rabinovich, A, 2020, "Upscaling capillary pressure curves for numerical modeling of gravity-capillary driven flow", in, Advances in Water Resources, 103639.

Chequer, L, and Bedrikovetsky, P, 2019, "Suspension-colloidal flow accompanied by detachment of oversaturated and undersaturated fines in porous media”, in, Chemical Engineering Science, vol.198, pp. 16-32.

Chequer, L, Bedrikovetsky, P, Carageorgos, T, Badalyan, A, and Gitis, V, 2019, “Mobilization of attached clustered colloids in porous media", in, Water Resources Research, vol. 55, pp. 5696-5714.

Chequer, L, Vaz, A, and Bedrikovetsky, P, 2018, "Injectivity decline during low salinity waterflooding due to fines migration", in , Journal of Petroleum Science and Engineering, vol. 165, pp. 1054-1072.

Chidambaram, S, Anandhan, P, Prasanna, M, V, Ramanathan, A, L, Srinivasamoorthy, K, and Kumar, S, G, 2012, "Hydrogechemical modelling for groundwater in Neyveli aquifer, Tamil Nadu, India using PHREEQC: A case study", in, Natural Resources Research, vol. 21, pp. 311-324. 
Choi, H, S, Park, H, C, Huh C, and Kang, S, G 2011, "Numerical simulation of fluid flow and heat transfer of supercritical $\mathrm{CO}_{2}$ in micro-porous media", in , Energy Procedia, vol. 4, pp. 3786-3793.

Civan, F 2007, Reservoir formation damage, 1st edn, Gulf Pub. Co., Houston, Tex. ISBN: 978-0-7506-77387.

Dasgupta, S., 2019. Implications of Transfer Zones in Rift Fault Propagation: Example from Cauvery Basin, Indian East Coast. In: S. Mukherjee, ed., Tectonics and Structural Geology: Indian Context, 1st ed. Switzerland: Springer Nature, pp.313-327.

De Silva, G, P, D, Ranjith, P, G, Perera, M, S, A, Dai, Z, X, and Yang, S, Q, 2017, "An experimental evaluation of unique $\mathrm{CO}_{2}$ flow behaviour in loosely held fine particles rich sandstone under deep reservoir conditions and influencing factors", in , Energy, vol. 119, pp. 121-137.

Du, Y, Fu, C, Pan, Z, Sang, S, Wang, W, Liu, S, Zhao, Y, and Zhang, J, 2020, "Geochemistry effects of supercritical $\mathrm{CO}_{2}$ and $\mathrm{H}_{2} \mathrm{O}$ on the mesopore and macropore structures of high-rank coal from the Qinshui Basin, China", in, International Journal of Coal Geology, vol. 223, pp. 103467.

Doster, F, Nordbotten, J, M, and Celia, M, A, 2013, "Impact of capillary hysteresis and trapping on vertically integrated models of $\mathrm{CO}_{2}$ storage", in, Advances in Water Resources, vol. 62, pp. 465-474.

Fan, L, and Liu, S, 2019, "Evaluation of permeability damage for stressed coal with cyclic loading: An experimental study", in, International Journal of Coal Geology, vol. 216, pp. 103338.

Ge, L, Soares, F, T, Mahoney, S, Hamilton, C, Khan, C, Steel, K, Rufford, T, E, and Rudolph, V, 2019, “Effect of oxidation and silane treatments of coal powders on relative permeability in packed coal beds", in, Journal of Natural Gas Science and Engineering, vol.69, pp. 102931. 
George, D, and Mallery, P., 2016. IBM SPSS Statistics 23 Step by Step: A simple Guide and Reference. T\&F India.

Godec, M, Koperna, G, Petrusak, R, and Oduinot, A, 2013, "Potential for enhanced oil recovery and $\mathrm{CO}_{2}$ storage in the Marcellus Shale in the Eastern United States", in, International Journal of Coal Geology, vol. 118 , pp. 95-104.

Gomes, E, R, Santos, A, and Lima, S, A, 2017, "Numerical modeling of straining: The role of particle and pore size distributions", in, Transport in Porous Media, vol. 120, pp. 535-551.

Guo, Z, Vu, P, H, N, and Hussain, F, 2018, "A laboratory study of the effect of creep and fines migration on coal permeability during single-phase flow", in, International Journal of Coal Geology, vol. 200, pp. 61-76.

Guo, Z, Hussain, F, and Cinar, Y, 2016, "Physical and analytical modeling of permeability decline in bituminous coal caused by fines migration during water production", in, Journal of Natural Gas Science and Engineering, vol. 35, pp. 331-346.

Guo, Z, Hussain, F, and Cinar, Y 2015, "Permeability variation associated with fines production from anthracite coal during water injection", in , International Journal of Coal Geology, vol. 147-148, pp. 46-57.

Han, G, Ling, K, Wu, H, Gao, F, Zhu, F, and Zhang, M, 2015, "An experimental study of coal-fines migration in Coalbed-methane production wells", in, Journal of Natural Gas Science and Engineering, vol. 26, pp. 1542-1548.

Huang, F, Kang, Y, You, L, Li, X, and You, Z 2018, "Massive fines detachment induced by moving gas-water interfaces during early stage two-phase flow in coalbed methane reservoirs", in, Fuel, vol. 222, pp. 193206. 
Huang, F, Kang, Y, You, Z, You, L, and Xu, C, 2017, "Critical conditions for massive fines detachment induced by single-phase flow in coalbed methane reservoirs: Modeling and experiments", in, Energy and Fuels, vol. 31, pp. 6782-6793.

Jin, Y, Zhang, J, Liu, X, Pan, J, and Liu, S, 2019, “Control mechanisms of self-affine, rough cleat networks on flow dynamics in coal reservoir”, in, Energy, vol. 189, pp. 116146.

Kalantariasl, A, Zeinijahromi, A, and Bedrikovetsky, P, 2014, "Axi-symmetric two-phase suspensioncolloidal flow in porous media during water injection", in, Industrial \& Engineering Chemistry Research, vol. 53, pp. 15763-15775.

Kanimozhi, B, Mahalingam, S, Pranesh, V, Kesavakumar, R, Senthil, S, Pradeep, S, Senthil, S, and Murugan, R, 2020, "Colloidal Release in High Temperature Porous Media with oversaturated fines during supercritical $\mathrm{CO}_{2}$ transport”, in, Journal of Petroleum Science and Engineering, vol.192, pp. 107345.

Kanimozhi, B, Thamizhmani, V, Pranesh, V, Senthil, S, and Selvakumar, T, A, 2019a, "Kaolinite fines colloidal flow in high temperature porous carbonate media during saline water injection", in, Journal of Petroleum Science and Engineering, vol. 175, pp. 775-784.

Kanimozhi, B, Prakash, J, Pranesh, R, V, and Mahalingam, S, 2019b, "Numerical and experimental investigation on the effect of retrograde vaporization on fines migration and drift in porous oil reservoir: roles of phase change heat transfer and saturation", in, Journal of Petroleum Exploration and Production Technology, vol. 9, pp. 2953-2963.

Kanimozhi, B, Prakash, J, Pranesh, V, Thamizhmani, V, and Vishnu, R, C, 2018, "Fines surface detachment and pore-throat entrapment due to colloidal flow of lean and rich gas condensates", in , Journal of Natural Gas Science and Engineering, vol. 56, pp. 42-50.

Karacan, C, O, and Warwick, P, D, 2019, "Assessment of coal mine methane (CMM) and abandoned mine methane (AMM) resource potential of longwall mine panels: Example from Northern Appalachian Basin, 
USA", in, International Journal of Coal Geology, vol.208, pp. 37-53.

Keshavarz, A, Badalyan, A, Carageorgos, T, Bedrikovetsky, P, and Johnson, R, 2015, "Stimulation of coal seam permeability by micro-sized graded proppant placement using selective fluid properties", in, Fuel, vol.144, pp. 228-236.

Keshavarz, A, Yang, Y, Badalyan, A, Johnson, R, and Bedrikovetsky, P, 2014, "Laboratory-based mathematical modelling of graded proppant injection in CBM Reservoirs", in, International Journal of Coal Geology, vol.32, pp. 1-16.

Kiyama, T, Nishimototo, S, Fujioka, M, Xue, Z, Ishijima, Y, Pan, Z, and Connell, L, D, 2011, “Coal swelling strain and permeability change with injecting liquid/supercritical $\mathrm{CO}_{2}$ and $\mathrm{N}_{2}$ at stress-constrained conditions", in , International Journal of Coal Geology, vol. 85, pp. 56-64.

Khilar, K and Fogler, H 1998, Migrations of fines in porous media, 1st edn, Kluwer Academic Publishers, Dordrecht. ISBN: 978-90-481-5115-8.

Koukouzas, N, 2007, "Mineralogy and geochemistry of diatomite associated with lignite seams in the Komnina Lignite Basin, Ptolemais, Northern Greece", in, International Journal of Coal Geology, vol. 71, pp. 276-286.

Kweon, $\mathrm{H}$, and Deo, M, 2017, "The impact of reactive surface area on brine-rock-carbon dioxide reactions in $\mathrm{CO}_{2}$ sequestration", in, Fuel, vol. 188, pp. 39-49.

Lee, J, H, Jeong, M, S, and Lee, K, S, 2019, "Incorporation of multi-phase solubility and molecular diffusion in a geochemical evaluation of the $\mathrm{CO}_{2}$ huff-n-puff process in liquid-rich shale reservoirs", in, Fuel, vol. 247, pp. 77-86. 
Mahalingam, S, Pranesh, V, Kanimozhi, B, Thamizhmani, V, and Selvakumar, T, A, 2019, "Subcritical $\mathrm{CO}_{2}$ effects on kaolinite fines transport in porous limestone media", in, Journal of Petroleum Exploration and Production Technology, pp. 1-9.

Mahdavi, S, and James, L, A, 2020, "High pressure and high-temperature study of $\mathrm{CO}_{2}$ saturated-water injection for improving oil displacement: mechanistic and application study", in , Fuel, vol. 262, pp. 116442.

Mahzari, P, and Sohrabi, M, 2017, "An improved approach for estimation of flow and hysteresis parameters applicable to WAG experiments", in, Fuel, vol. 197, pp. 359-372.

Malgaresi, G, Collins, B, Alvaro, P, and Bedrikovetsky, P 2019, "Explaining non-monotonic retention profiles during flow of size-distributed colloids", in , Chemical Engineering Journal, vol. 375, pp. 121984.

Mazumder, S., Tep, B., Pangtey, K. and Mitra, D., 2019. Basement Tectonics and Shear Zones in Cauvery Basin (India): Implications in Hydrocarbon Exploration. In: S. Mukherjee, ed., Tectonics and Structural Geology: Indian Context, 1st ed. Switzerland: Springer Nature, pp.279-313.

Ming, X-R, Liu, L, Yu, L, Bai, H-G, Yu, Z-C, Liu, N, Yang, H-X, Wang, F-G, and Li, B-X, 2017, “Thin-film dawsonite in Jurassic coal measure coal measure strata of the Yaojie coalfield, Minhe Basin, China: A natural analogue for mineral carbon storage in wet supercritical $\mathrm{CO}_{2}{ }^{\prime \prime}$, in, International Journal of Coal Geology, vol. 180, pp. 83-99.

Mitchell, T, R, and Leonardi, C, R, 2016, "Micromechanical investigation of fines liberation and transport during coal seam dewatering”, in, Journal of Natural Gas Science and Engineering, vol.35, pp. 1101-1120.

Moore, T, A, 2012, “Coalbed methane: A review”, in, International Journal of Coal Geology, vol. 101 pp. 3681. 
Mosavat, $\mathrm{N}$, and Torabi, $\mathrm{F}, 2014$, "Application of $\mathrm{CO}_{2}$-straurated water flooding as a prospective safe $\mathrm{CO}_{2}$ storage strategy", in, Fuel, vol. 63 pp. 5408-5419.

Mukherjee S (2015a) Atlas of structural geology. Elsevier, Amsterdam. ISBN: 978-0-12-420152-1.

Mukherjee S (2015b) Petroleum geosciences: Indian contexts. Springer Geology. ISBN978-3-319-03119-4.

Murthy, H, P, S, Subrahmanyam, A, V, and Bhaskar Rao, H, V, 1950, "Studies on Indian refractory clays: Part IV-some clays from Madras State”, in, Transactions of Indian Ceramic Society, vol. 44, pp. 82-88.

Narasimhan, A , (2013), Essentials of heat and fluid flow in porous media, 1 st edn, CRC Press, Boca Raton, Fla. ISBN: 978-93-8212-721-5.

Narinesingh, J, and Alexander, D, 2014, " $\mathrm{CO}_{2}$ enhanced oil recovery and geological sequestration in condensate reservoir: A simulation study of the effects of injection pressure on condensate recovery from reservoir and $\mathrm{CO}_{2}$ storage efficiency”, in, Energy Procedia, vol. 63, pp. 3107-3115.

NLC. (2018). Neyveli Lignite Corporation Ltd. Corporate Presentation.

Oikonomopoulos, I, K, Perraki, M, Tougiannidis, N, Perraki, T, Frey, M, J, Antoniadis, P, and Ricken, W, 2013, "A comparative study on structural differences of xylite and matrix lignite lithotypes by means of FT-IR, XRD, SEM, and TGA analysis: An example from the Neogene Greek lignite deposits", in, International Journal of Coal Geology, vol. 115, pp. 1-12.

Olea, $\mathrm{R}, \mathrm{A}, 2 \mathrm{2015}$, “ $\mathrm{CO}_{2}$ retention values in enhanced oil recovery", in, Journal of Petroleum Science and Engineering, vol. 129, pp. 23-28. 
Oliveira, M, A, Vaz, A, S, L, Siqueira, F, D, Yang, Y, You, Z, and Bedrikovetsky, P, 2014, "Slow migration of mobilised fines during flow in reservoir rocks: Laboratory study", in, Journal of Petroleum Science and Engineering, vol. 122, pp. 534-541.

Othman, F, Yu, M, Kamali, F, and Hussain, F 2018, "Fines migration during supercritical $\mathrm{CO}_{2}$ injection in sandstone", in, Journal of Natural Gas Science and Engineering, vol. 56, pp. 344-357.

Pandya, K, Bulsari, S, and Sinha, S., (2014). SPSS in Simple Steps. Dreamtech Press.

Pranesh, V, Balasubramanian, S, Kumar, R, S, Sakthivel, R, Rajkumar, P, and Ravikumar, S, 2019, "Kaolinite flakes and coal fines production in Neyveli lignite core under ambient conditions: A case study of Neyveli Lignite Field at Cauvery Basin, India”, in, Journal of Natural Gas Science and Engineering, vol.64, pp. 7280.

Pranesh, V, and Ravikumar, S, 2019, "Heat conduction and liberation of porous rock formation associated with fines migration in oil reservoir during waterflooding", in, Journal of Petroleum Science and Engineering, vol. 175, pp. 508-518.

Pranesh, V, 2018, "Subsurface $\mathrm{CO}_{2}$ storage estimation in Bakken tight oil and Eagle Ford shale gas condensate reservoirs by retention mechanism", in, Fuel, vol. 215, pp. 580-591.

Pranesh, V, Thamizhmani, V, Ravikumar, S, and Padakandla, S 2018, "Multiple linear regression theory based performance optimization of Bakken and Eagle Ford shale oil reservoirs", in , International Journal of Engineering Research and Applications, vol. 8, pp. 2248-9622.

Pranesh, V, (2016), Statistical Modelling of American Unconventional Petroleum Reservoirs: Bakken and Eagle Ford Shale Fields, Lambert Academic Publishing, Germany. ISBN: 978-3-330-01007-9.

Prempeh, K, O, K, Chequer, L, Badalyan, A, and Bedrikovetsky, P, 2020, "Effects of the capillary-entrapped phase on fines migration in porous media", in, Journal of Natural Gas Science and Engineering, vol. 73, pp. 103047. 
Pirzada, M, A, Zoorabadi, M, Ramandi, H, L, Canbulat, I, and Roshan, H, 2018, "CO ${ }_{2}$ sorption induced damage in coals in unconfined and confined stress states: A micrometer to core scale investigation", in , International Journal of Coal Geology, vol. 198, pp. 167-176.

Raha, S, Khilar, C, K, Kapur, P, C and Pradip, P, 2007, "Regularities in pressure filtration of fine and colloidal suspension", in, International Journal of Mineral Processing, vol. 84, pp. 348-360.

Rao, D, S, Nagendra, R, Mohideen, E, R, and Nayak, B, R 2009, “Characterization of Sulphides Patches from the Neyveli Lignite Deposit ", in , Journal of Minerals \& Materials Characterization \& Engineering, vol. 8, pp. 223-228.

Rabinovich, A, Bedrikovetsky, P, and Tartakovsky, D, M, 2020, "Analytical model for gravity segregation of horizontal multiphase flow in porous media", in, Physics of Fluids, vol. 32, pp. 046602.

Rabinovich, A, Itthisawatpan, $\mathrm{K}$, and Durlofsky, L, J, 2015, "Upscaling of $\mathrm{CO}_{2}$ injection into brine with capillary heterogeneity effects", in, Journal of Petroleum Science and Engineering, vol. 134, pp. 60-75.

Ramesh, K, Aravind Raj, G, Ashok Kumar, K, Janarthan, V, R, and Prakash, S, M, 2019, "Groundwater management in and around NLCIL mines", in, International Journal of Current Engineering and Scientific Research, vol. 6, pp. 2394-0697.

Rathi, R, Lavania, M, Singh, N, Sarma, P, M, Kishore, P, Hajra, P, and Lal, B, 2019, “Evaluating indigenous diversity and its potential for microbial methane generation from thermogenic coal bed methane reservoir", in, Fuel, vol. 250, pp. 362-372.

Russell, T, and Bedrikovetsky, P, 2018, "Colloidal-suspension flows with delayed fines detachment: Analytical model \& laboratory study”, in, Chemical Engineering Science, vol. 190, pp. 98-109. 
Russell, T, Wong, K, Zeinijahromi, A, and Bedrikovetsky, P, 2018, "Effects of delayed particles detachment on injectivity decline due to fines migration", in , Journal of Hydrology, vol. 564, pp. 1099-1109.

Russell, T, Pham, D, Neishaboor, M, T, Badalyan, A, Behr, A, Genolet, L, Kowollik, P, Zeinijahromi, A and Bedrikovetsky, P, 2017, "Effects of kaolinite in rocks on fines migration", in, Journal of Natural Gas Science and Engineering, vol. 45, pp. 243-255.

Sacramento, R, N, Yang, Y, You, Z, Waldmann, A, Martins, A, L, Vaz, A, S, L, Zithra, P, L, J, and Bedrikovetsky, $P_{\text {, }} 2015$, “Deep bed and cake filtration of two-size particle suspension in porous media”, in, Journal of Petroleum Science and Engineering, vol. 126, pp. 201-210.

Saghafi, A, Faiz, M, and Roberts, D, 2007, " $\mathrm{CO}_{2}$ storage and gas diffusivity properties of coals from Sydney Basin, Australia", in, International Journal of Coal Geology, vol. 70, pp. 240-254.

Sampath, K, H, S, M, Sin, I, Perera, M, S, A, Matthai, S, K, Ranjith, P, G, and Dong-yin, L, 2020, "Effect of supercritical $\mathrm{CO}_{2}$ interaction time on the alterations in coal pore structure", in, Journal of Natural Gas Science and Engineering, vol. 76, pp. 103214.

Sampath, K, H, S, M, Perera, M, S, A, Lin, D, Y, Ranjith, P, G, and Matthai, S, K, 2019, "Evaluation of mechanical behaviour of brine $+\mathrm{CO}_{2}$ saturated brown coal under mono-cyclic uni-axial compression", in, Engineering Geology, vol. 263, pp. 105312.

Sander, R, Connell, L, D, Pan, Z, Camilleri, M, Heryanto, D, and Lupton, N, 2014, "Coreflooding experiments of $\mathrm{CO}_{2}$ enhanced coalbed methane recovery", in, International Journal of Coal Geology, vol. 131, pp. 113125.

Santos, A, Bedrikovetsky, P and Fontoura, S 2008, "Analytical micro model for size exclusion: Pore blocking and permeability reduction", in, Journal of Membrane Science, vol. 308, no. 1-2, pp. 115-127. 
Santos, A and Bedrikovetsky, P 2006, "A Stochastic Model for Particulate Suspension Flow in Porous Media", in , Transport in Porous Media, vol. 62, no. 1, pp. 23-53.

Seidle, J., 2011. Fundamentals of Coalbed Methane Reservoir Engineering. PennWell Books.

Senthil, S, Mahalingam, S, Ravikumar, S, and Pranesh, V 2019, "Adiabatic behavior of gas wells due to natural reservoir fines migration: analytical model and CFD study", in, Journal of Petroleum Exploration and Production Technology, vol. 9, p. 2863-2876.

Seyyedi, M, Giwelli, A, White, C, Esteban, L, Verrall, M, and Clennell, B, 2020, "Effects of geochemical reactions on multiphase flow in porous media during $\mathrm{CO}_{2}$ injection", in, Fuel, vol. 269, pp. 117421.

Schembre, J and Kovscek, A 2005, "Mechanism of Formation Damage at Elevated Temperature", in , Journal of Energy Resources Technology, vol. 127, no. 3, p. 171.

Sinha, M, K, 1994, “Utilisation study of two Indian plastic fire clays”, in, Inter Ceram, vol. 43, pp. 17-20.

Sinha, M, K, and Guha, S, K, 1990, "Mineralogical analysis of five plastic fire clays: Chemical analysis and x-ray diffraction studies", in, Transactions of Indian Ceramic Society, vol. 49, pp. 100-102.

Sokama-Neuyam, Y, A, Ginting, P, U, R, Timilsina, B, and Ursin, J, R, 2017, "The impact of fines mobilization on $\mathrm{CO}_{2}$ injectivity: An experimental study", in, International Journal of Greenhouse Gas Control, vol. 65, pp. 195-202.

Teng, T, Wang, J, G, Gao, F, Ju, Y, and Jiang, C, 2016, "A thermal sensitive permeability model for coal-gas interactions including thermal fracturing and volatilization", in , Journal of Natural Gas Science and Engineering, vol. 32, pp. 319-33. 
Teruel, F, E, and Díaz, L, 2013, "Calculation of the interfacial heat transfer coefficient in porous media employing numerical simulations", in, International Journal of Heat and Mass Transfer, vol. 60, pp. 406412.

Valentim, B, Flores, D, Guedes, A, Shreya, N, Paul, B, and Ward, C, R 2016, "Vermicular kaolinite relics in fly ash derived from Bakaro and Jharia coals (Jharkhand, India)", in , International Journal of Coal Geology, vol. 162, pp. 151-157.

Vaz, A, Bedrikovetsky, P, Fernandez, P, D, Badalyan, A, and Carageorges, T, 2017, "Determining the model parameters for non-linear deep-bed filtration using laboratory pressure measurements", in, Journal of Petroleum Science and Engineering, vol. 151, pp. 421-433.

Vedachalam, N, Srinivasalu, S, Rajendran, G, Ramadass, G, A, and Atmanand, M, A, 2015, "Review of unconventional hydrocarbon resources in major energy consuming countries and efforts in realizing natural gas hydrates as a future source of energy”, in, Journal of Natural Gas Science and Engineering, vol. 26, pp. 163-175.

Veevers J. J, and Tewari R. C, 1995, "Gondwana master basin of peninsular India between Tethys and the interior of the Gondwanaland Province of Pangea". Geological Society of America Memoir, pp 72-187.

Verma, 0, 2015, "Cretaceous vertebrate fauna of the Cauvery Basin, southern India: Palaeodiversity and palaeobiogeographic implications", in, Palaeogeography, Palaeoclimatology, Palaeoecology, vol. 41, pp. 53-67.

Wang, D, Zhang, P, Wei, J, and Yu, C, 2020, "The seepage properties and permeability enhancement mechanism in coal under temperature shocks during unloading confining pressure", in , Journal of Natural Gas Science and Engineering, vol. 77, pp. 103242. 
Wang, B, Qin, Y, Shen, J, Wang, G, Zhang, Q, and Liu, M, 2019, “Experimental study on water sensitivity and salt sensitivity of lignite reservoir under different $\mathrm{pH}^{\prime \prime}$, in, Journal of Petroleum Science and Engineering, vol. 172, pp. 1202-1214.

Wang, Z, Su, W, X, Tang, and Wu, J, 2018, "Influence of water invasion on methane adsorption behaviour of coal”, in, International Journal of Coal Geology, vol.197, pp. 74-83.

Wang, $\mathrm{K}, \mathrm{Xu}, \mathrm{T}$, Wang, $\mathrm{F}$, and Tian, $\mathrm{H}, 2016$, "Experimental study of $\mathrm{CO}_{2}$ brine-rock- interaction during $\mathrm{CO}_{2}$ sequestration in deep coal seams", in, International Journal of Coal Geology, vol. 154-55, pp. 265-274.

Wdowin, M, Tarkowski, R, and Franus, W, 2014, "Determination of changes in the reservoir and cap rocks of the Chabowo Anticline caused by $\mathrm{CO}_{2}$-brine-rock interactions", in, International Journal of Coal Geology, vol. 130, pp. 79-88.

Wong, S, Macdonald, D, Andrei, S, Gunter, W, D, Deng, X, Law, D, Ye, J, Feng, S, Fan, Z, and Ho, P, 2010, "Conceptual economics of full scale enhanced coal bed methane production and $\mathrm{CO}_{2}$ storage in anthracite coals at South Qinshui basin, Shanxi, China", in, International Journal of Coal Geology, vol. 82, pp. 280-286.

Xie, Q, Saeedi, A, Piane, C, D, Esteban, L, and Brady, P, V, 2017, "Fines migration during $\mathrm{CO}_{2}$ injection: Experimental results interpreted using surface forces", in, International Journal of Greenhouse Gas Control, vol. 65, pp. 32-39.

Xu, R, Prodanović, M, and Landry, C, J, 2019, "Study of subcritical and supercritical gas adsorption behavior in different nanapore systems in shale using lattice Boltzmann methods", in, International Journal of Coal Geology, vol. 212, pp. 103263.

Yang, S, Russell, T, Badalyan, A, Schacht, U, Woolley, M, and Bedrikovetsky, P, 2019, “Characterization of fines migration system using laboratory pressure measurements", in, Journal of Natural Gas Science and Engineering, vol. 65, pp. 108-124. 
Yang, Y, Siqueira, F, Vaz, A, You, Z and Bedrikovetsky, P 2016, "Slow migration of detached fine particles over rock surface in porous media", in , Journal of Natural Gas Science and Engineering, vol. 34, pp. 11591173.

You, Z, Yang, Y, Badalyan, A, Bedrikovetsky, P, and Hand, M, 2016, "Mathematical modelling of fines migration in geothermal reservoirs", in, Geothermics, vol. 59, pp. 123-133.

You, Z, Osipov, Y, Bedrikovetsky, P, and Kuzmina, L, 2014, "Asymptotic model for deep bed filtration", in, Chemical Engineering Journal, vol. 258, 374-385.

Yu, M, Hussain, F, Arns, J, Y, Bedrikovetsky, P, Genolet, L, Behr, A, Kowollik, P, and Arns, C, H, 2018, "Imaging analysis of fines migration during water flow with salinity alteration", in, Advances in Water Resources, vol. 121, pp. 150-161.

Zeinijahromi, A, Farajzadeh, R, Bruining, J, H, and Bedrikovetsky, P, 2016, "Effect of fines migration on oilwater relative permeability during two-phase flow in porous media", in, Fuel, vol. 176, pp. 222-236.

Zeinijahromi, A, Vaz, A and Bedrikovetsky, P 2012, "Well impairment by fines migration by gas fields", in , Journal of Petroleum Science and Engineering, vol. 88-89, pp. 125-135.

Zhang, S, Xu, X, Liu, C, and Dang, C, 2020, "A review on application and heat transfer enhancement of supercritical $\mathrm{CO}_{2}$ in low-grade heat conversion", in , Applied Energy, vol. 269, pp. 114962.

Zhang, X, G, Ranjith, P, G, Ranathunga, A, S, and Li, D, Y, 2019a, "Variation of mechanical properties of bituminous coal under $\mathrm{CO}_{2}$ and $\mathrm{H}_{2} \mathrm{O}$ saturation", in , Journal of Natural Gas Science and Engineering, vol. 61, pp. 158-168. 
Zhang, Y, Lebedev, M, Jing, Y, Yu, H, and Iglauer, S, 2019b, "In-situ X-ray micro-computed tomography imaging of the microstructural changes in water-bearing medium rank coal by supercritical $\mathrm{CO}_{2}$ flooding", in, International Journal of Coal Geology, vol. 203, pp. 28-35.

Zhang, Z, Chen, X, Qian, Y, Liu, Q, Lv, W, Luo, M, and Fan, X, 2017, “Experimental study of $\mathrm{CO}_{2}$ storage in water-flooded oilfields", in, Petroleum Research, vol. 2, pp. 378-382.

Zhang, Y, Lebedev, M, Sarmadivaleh, M, Barifcani, A, Rahman, T, and Iglauer, S, 2016, "Swelling effect on coal microstructure and associated permeability reduction", in, Fuel, vol. 182, pp. 568-576.

Zhao, J, Tang, D, Lin, W, Qin, Y, and Xu, H, 2019, "In-situ stress distribution and its influence on the coal reservoir permeability in the Hancheng area, eastern margin of the Ordos Basin, China", in , Journal of Natural Gas Science and Engineering, vol. 61, pp. 119-132.

Zhao, L, Ward, C, R, French, D, Graham, I, T, Dai, S, Yang, C, Xie, P and Zhang, S 2018, "Origin of a kaolinite$\mathrm{NH}_{4}$-illite-pyrophyllite-chlorite assemblage in a marine -influenced anthracite and associated strata from the Jincheng Coalfield, Qinshui Basin, Northern China", in , International Journal of Coal Geology, vol. 185 , pp. 61-78.

Zhao, X, Liu, S, A, Sang, S Pan, Z, Zhao, W, Hu, Q and Yang, Y, 2016, "Characteristics and generation mechanism of coal fines in coalbed methane wells in the Southern Qinshui Basin, China", in, Journal of Natural Gas Science and Engineering, vol. 34, pp. 849-863.

Zheng, L, Su, G, Zhonghui, L, Peng, R, Wang, L, Wei, P, and Han, S, 2018, "The wellbore instability control mechanism of fuzzy ball drilling fluids for coal bed methane wells via bonding formation", in, Journal of Natural Gas Science and Engineering, vol. 56, pp. 107-120.

Zunsheng, J, Lifa, Z, Runmin, G, Tingting, L, Hong, W, Wang, H, McLaughin, F, Bentley, R, and Quillian, S, 2014, "Opportunity and challenges of integrated enhanced oil recovery using $\mathrm{CO}_{2}$ flooding with geological 
$\mathrm{CO}_{2}$ storage in the Ordos Basin, China”, in, Energy Procedia, vol. 63, pp. 7761-7771.

\section{Figures}

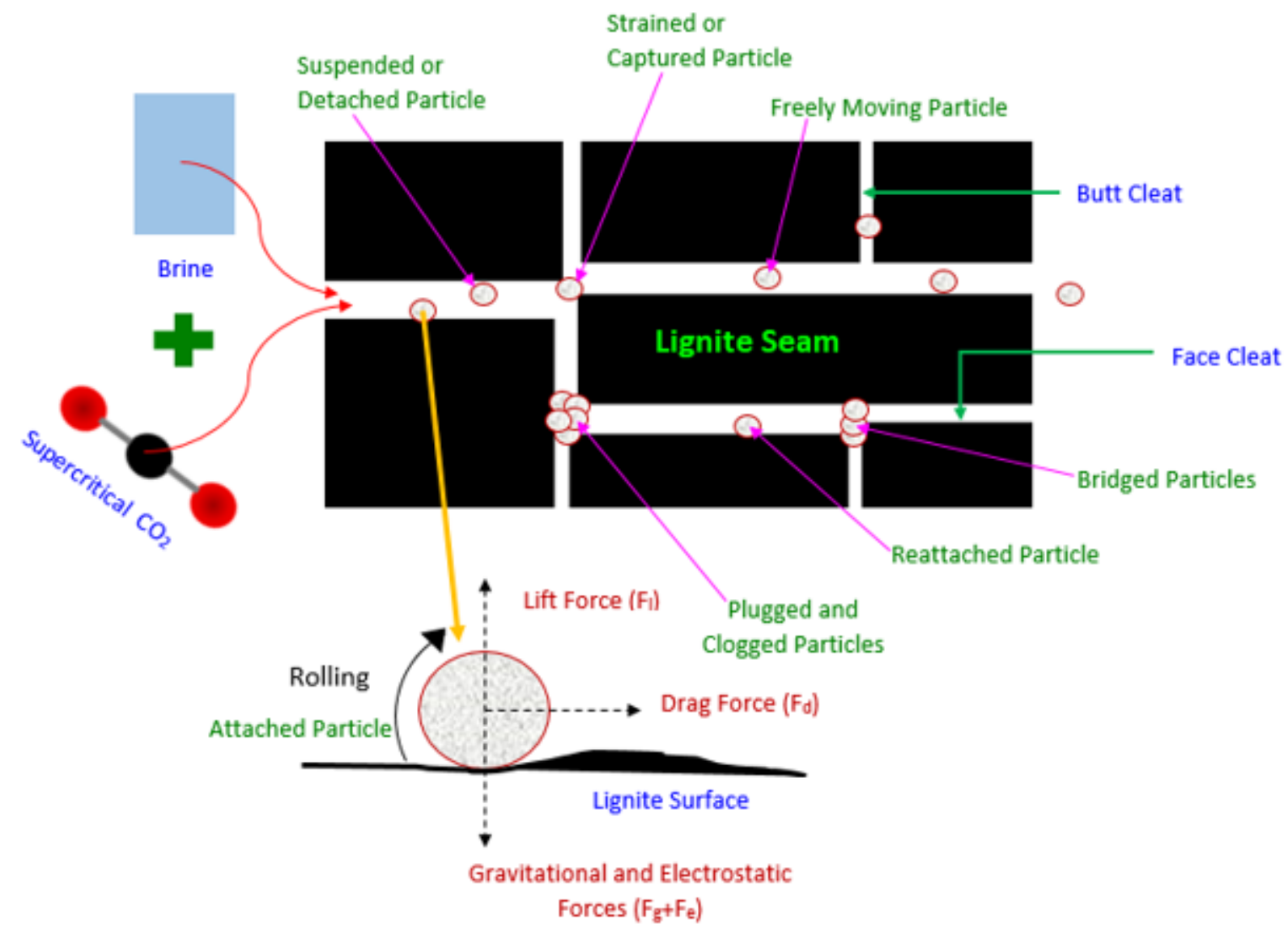

Figure 1

Schematic diagram of kaolinite fines behaviour in lignite seam during WAG (Brine + CO2) injection 


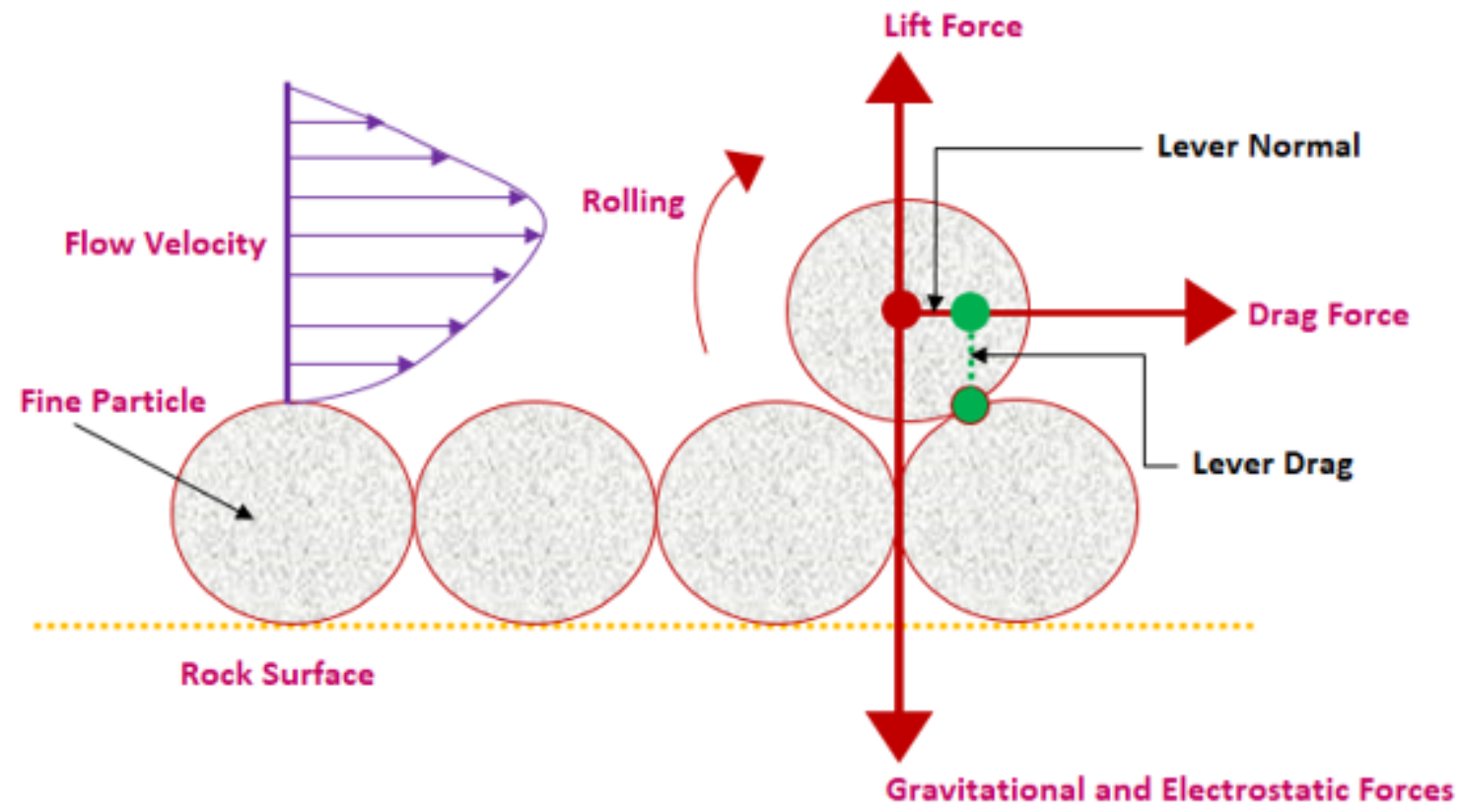

Figure 2

Modified schematic diagram of fines behaviour over rock surface under permeating fluid flow velocity, modified models of Mitchell and Leonardi (2016) and Bedrikovetsky et al. (2011)
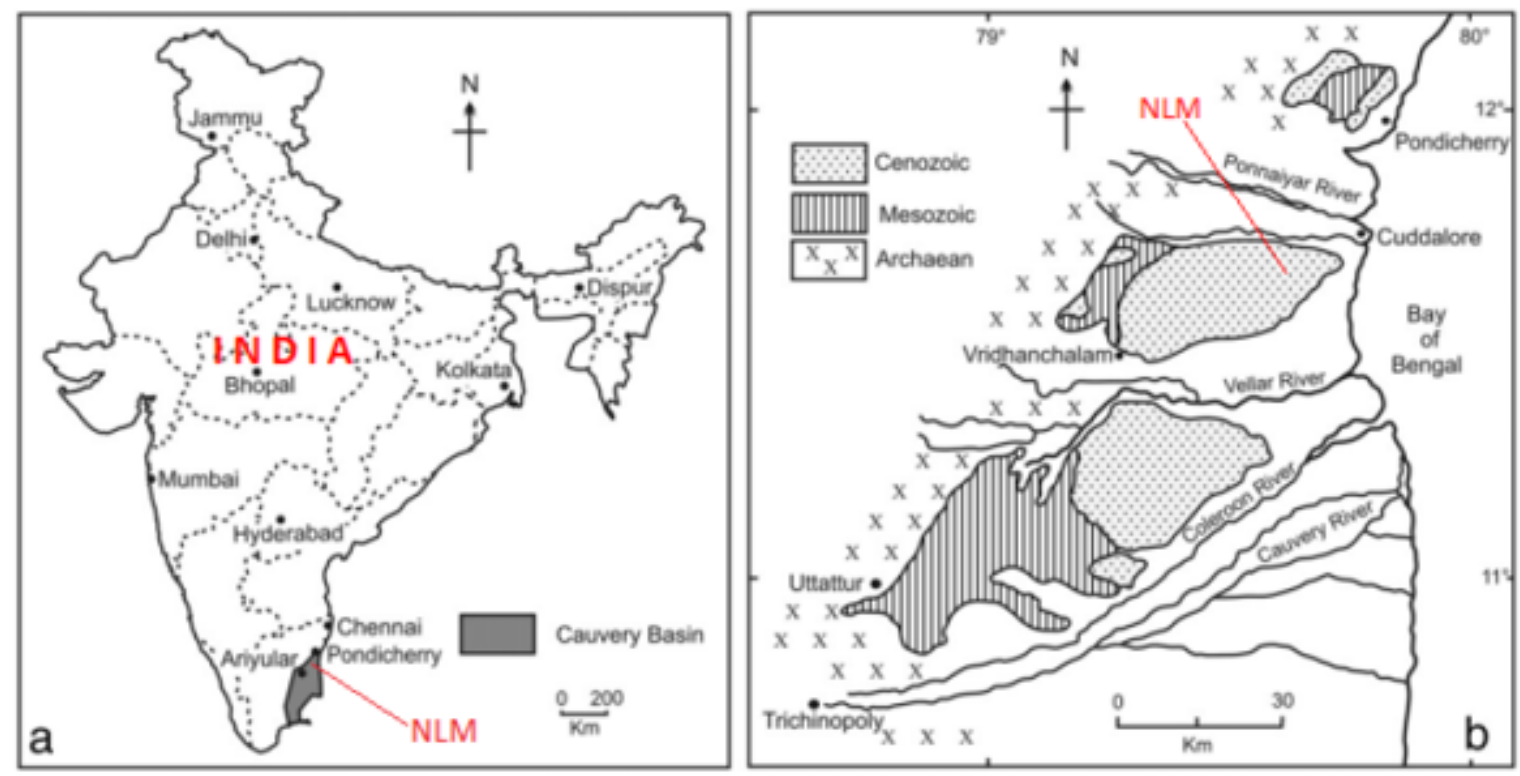

Neyveli Lignite Mine

\section{Figure 3}

a) Typical Indian map showing Cauvery Basin, b) Cauvery Basin map indicating three sub basins such as Pondicherry, Vridhachalam and Ariyalur (Verma 2015) 


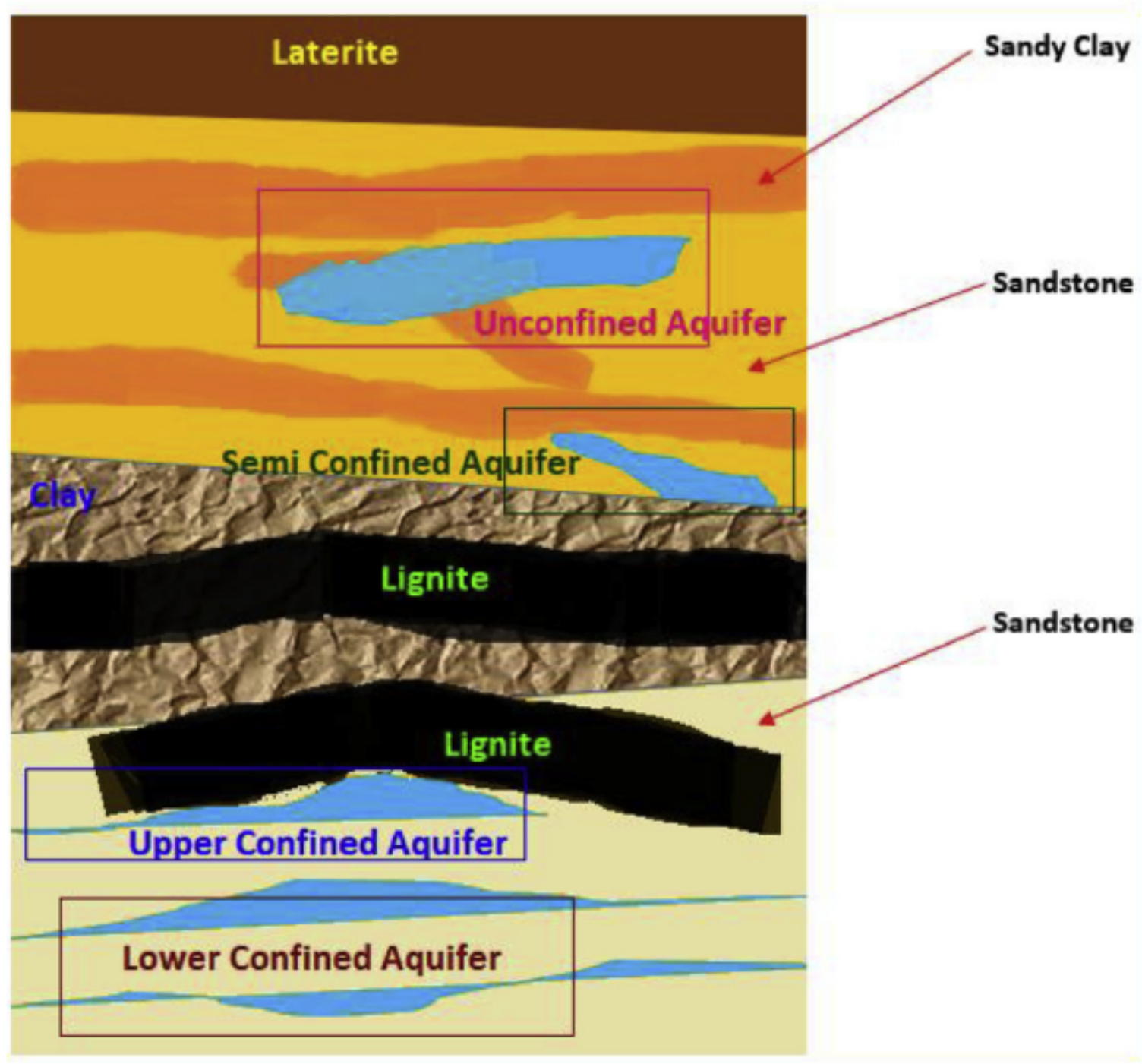

Figure 4

Schematic diagram of geological and hydrological cross section of Neyveli lignite formation (Pranesh et al. 2019) 


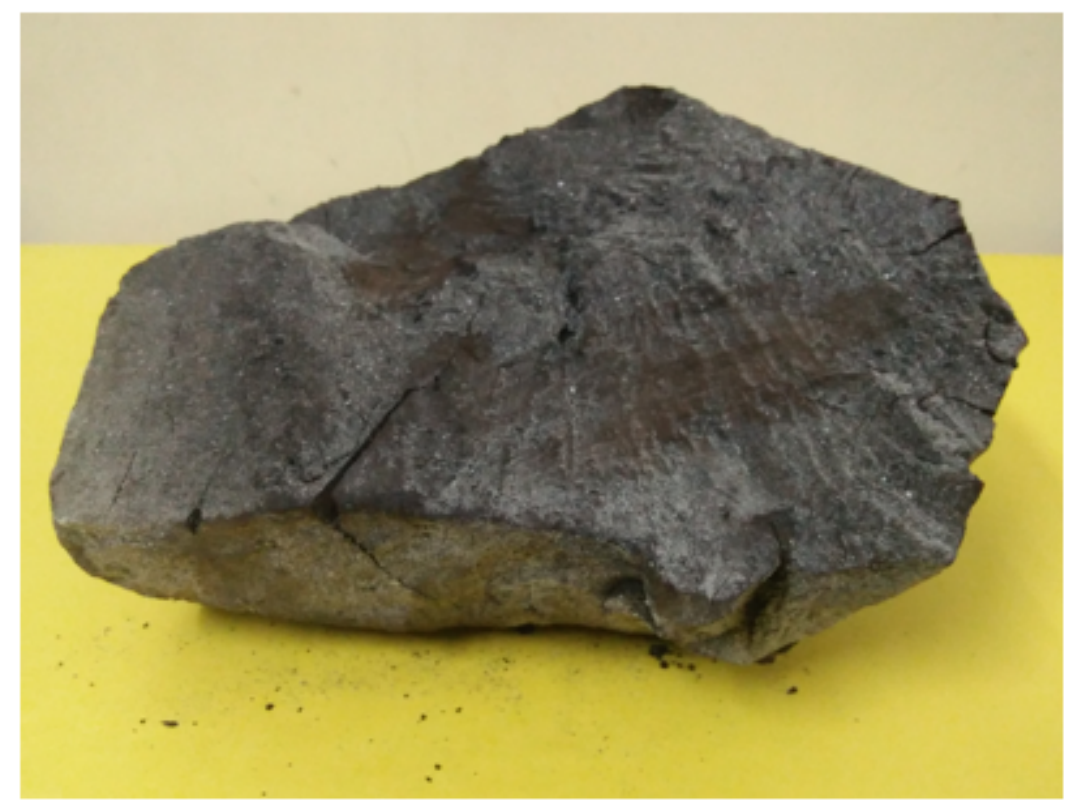

Figure 5

Typical photograph of Neyveli lignite rock

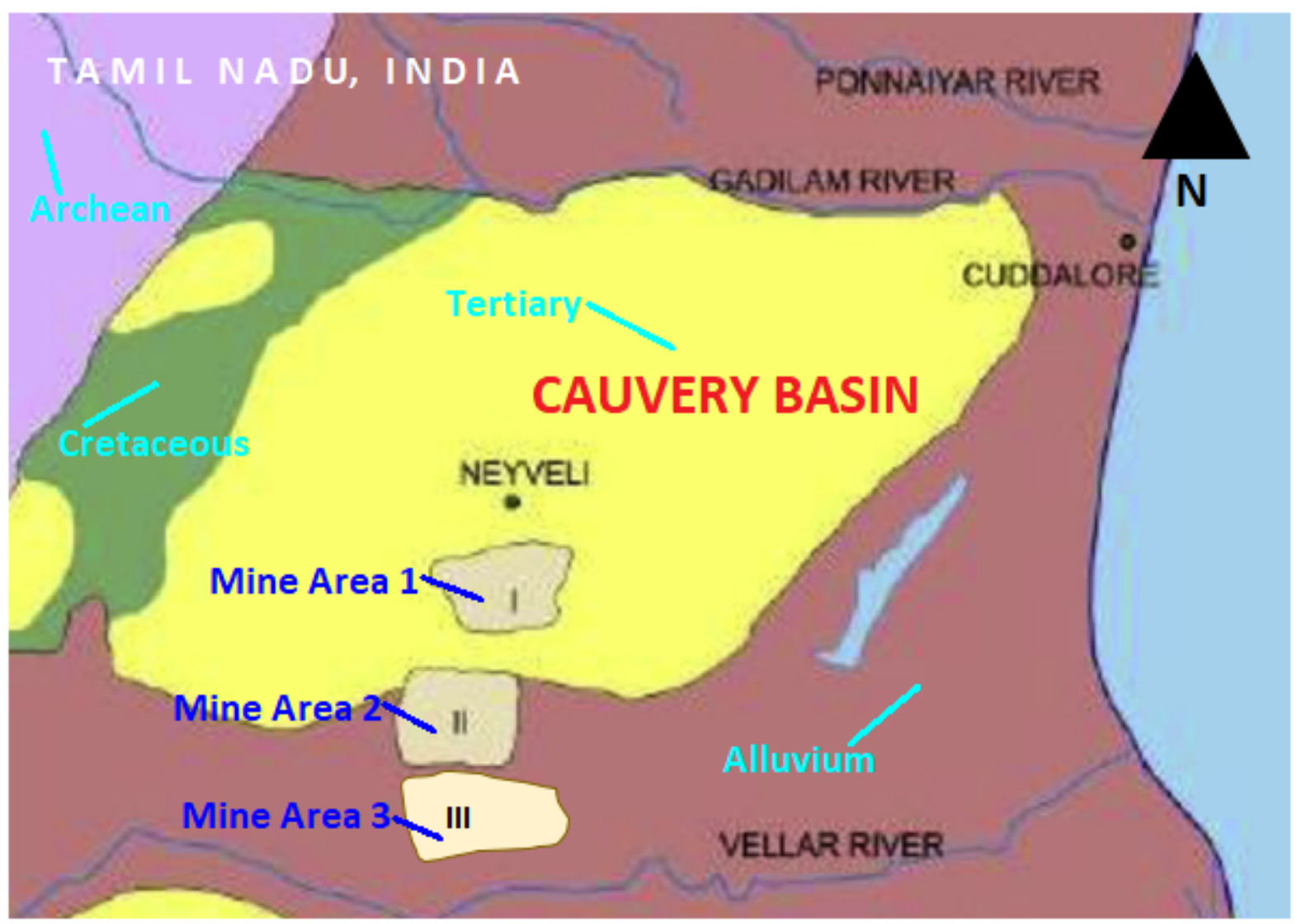

Figure 6 
Geological map of Neyveli lignite field showing three different mine areas, modified map of Pranesh et al. 2019

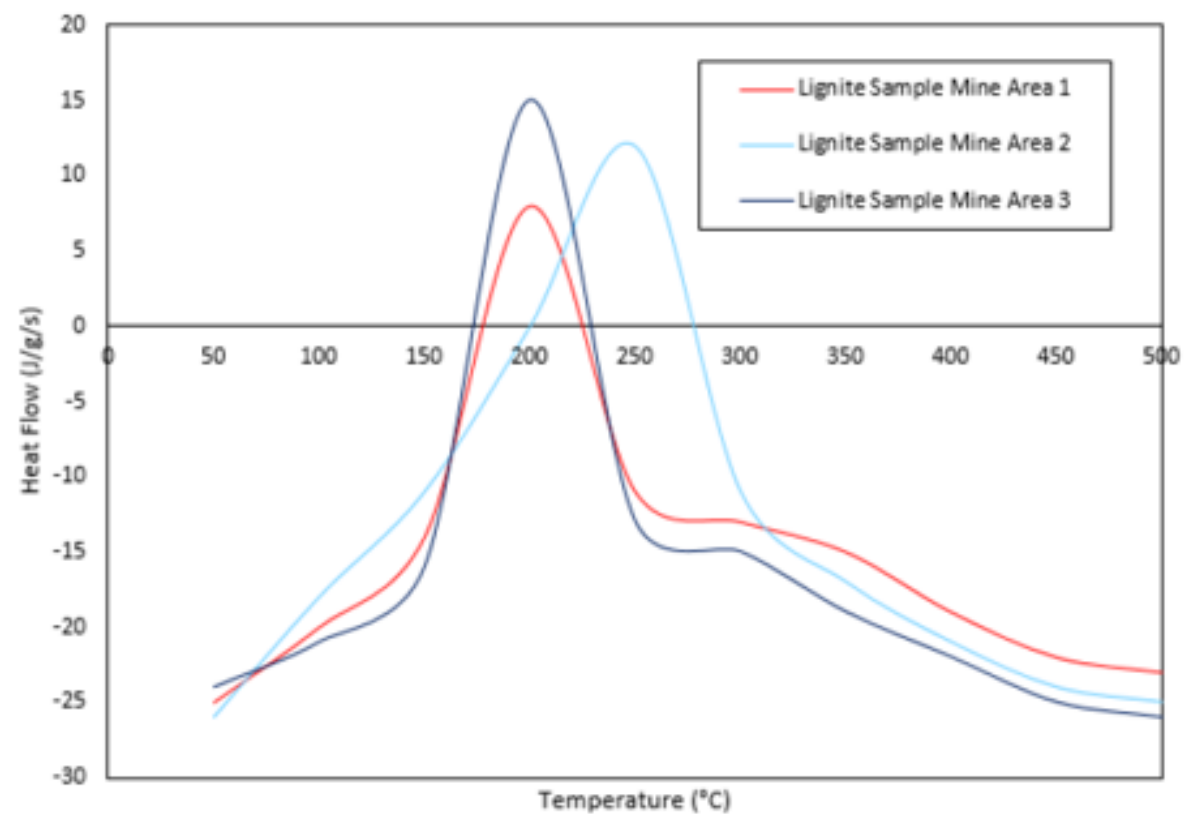

Figure 7

DSC profile of Neyveli lignite rocks

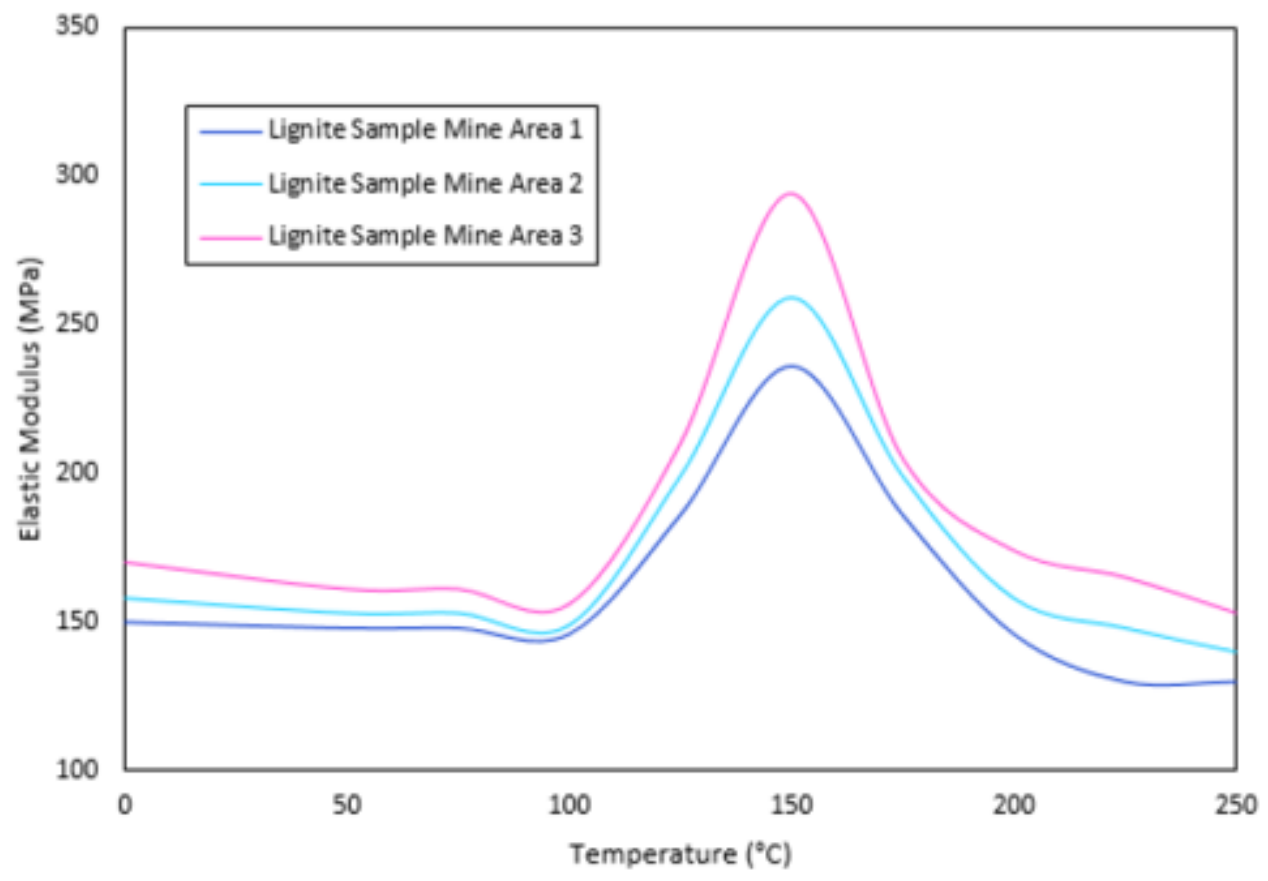

Figure 8

TMA profile of Neyveli lignite rocks 
a)

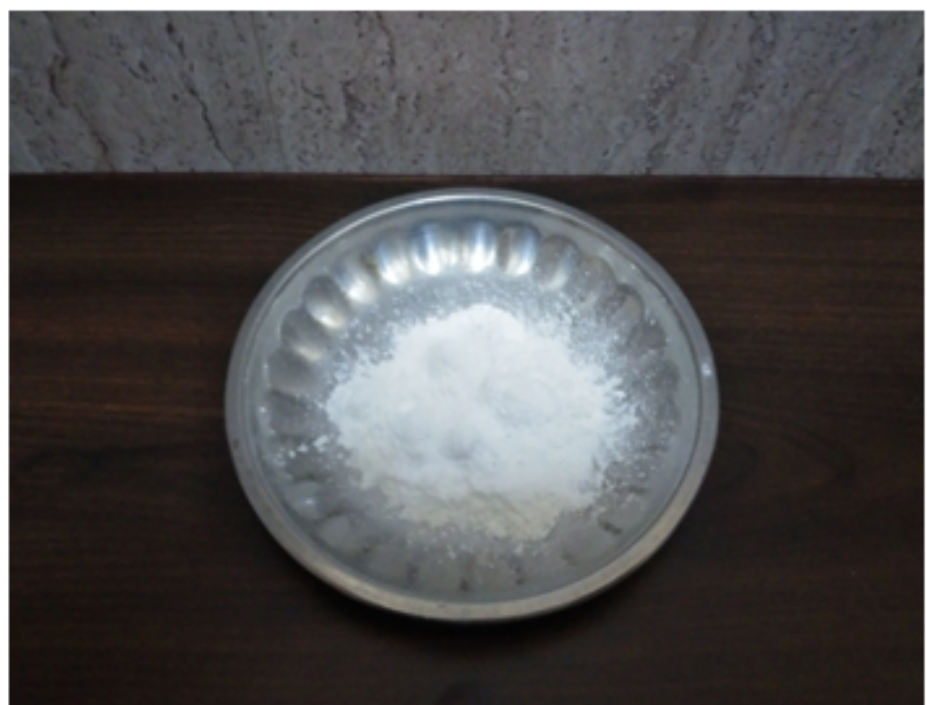

b)

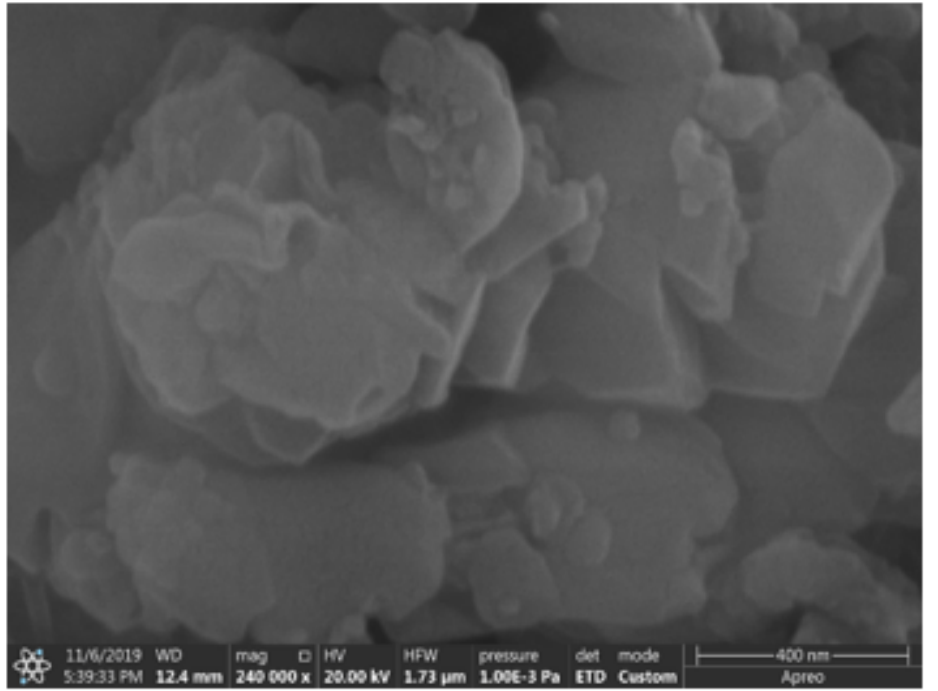

Figure 9

a) Photograph of typical kaolinite clay under 200 mesh size, b) A microstructural image of kaolinite fines under 400 nm magnification (Kanimozhi et al. 2020) 
a)

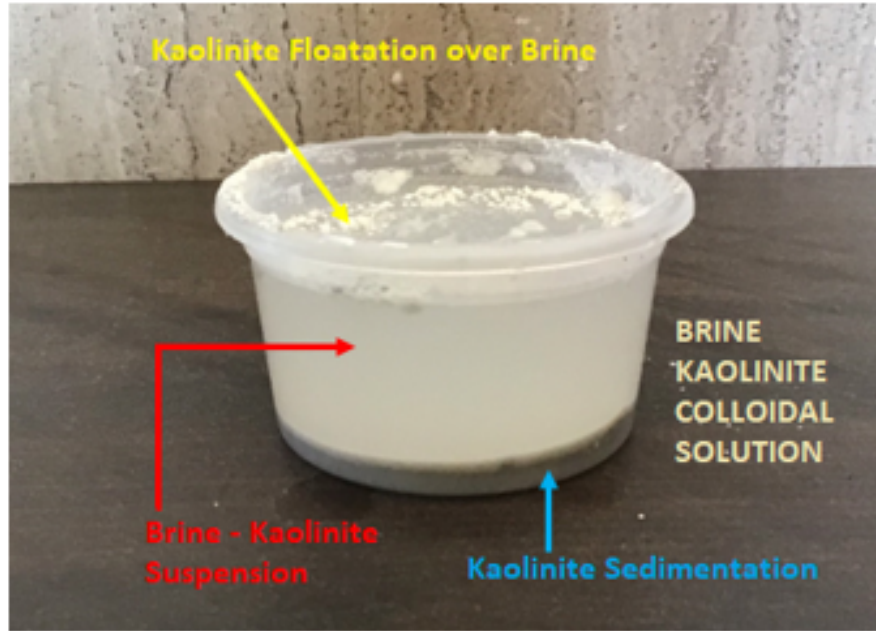

b)

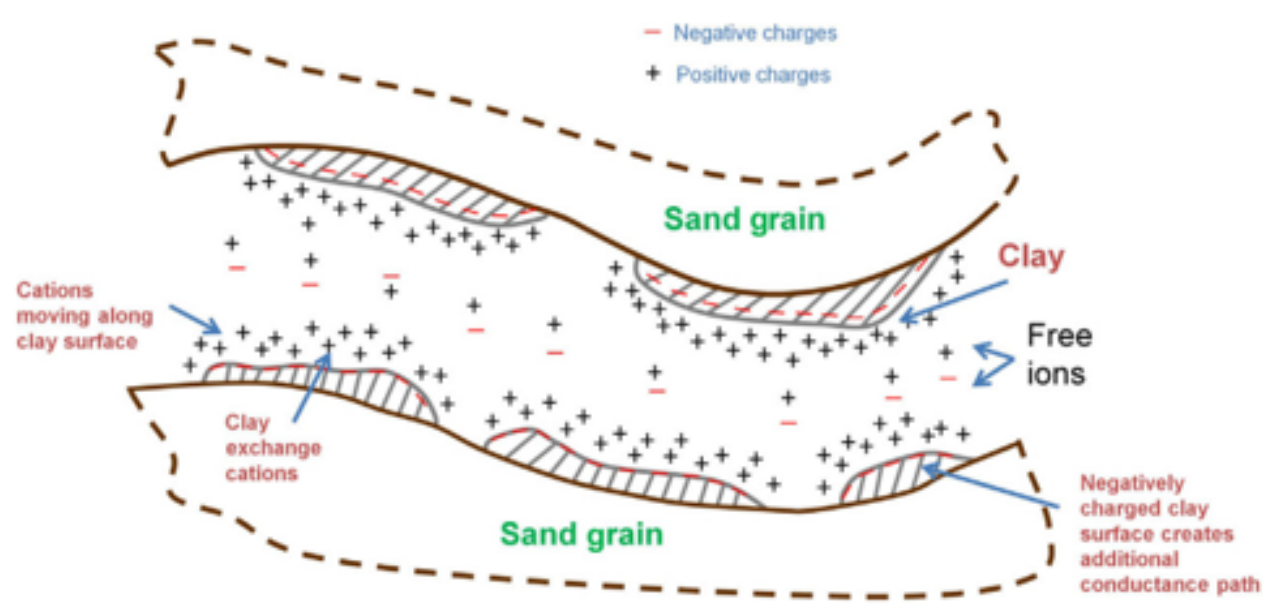

Figure 10

a) Photograph of brine kaolinite colloidal solution, b) Pore and clay ion mobility in shaly sand (McPhee et al. 2015) 


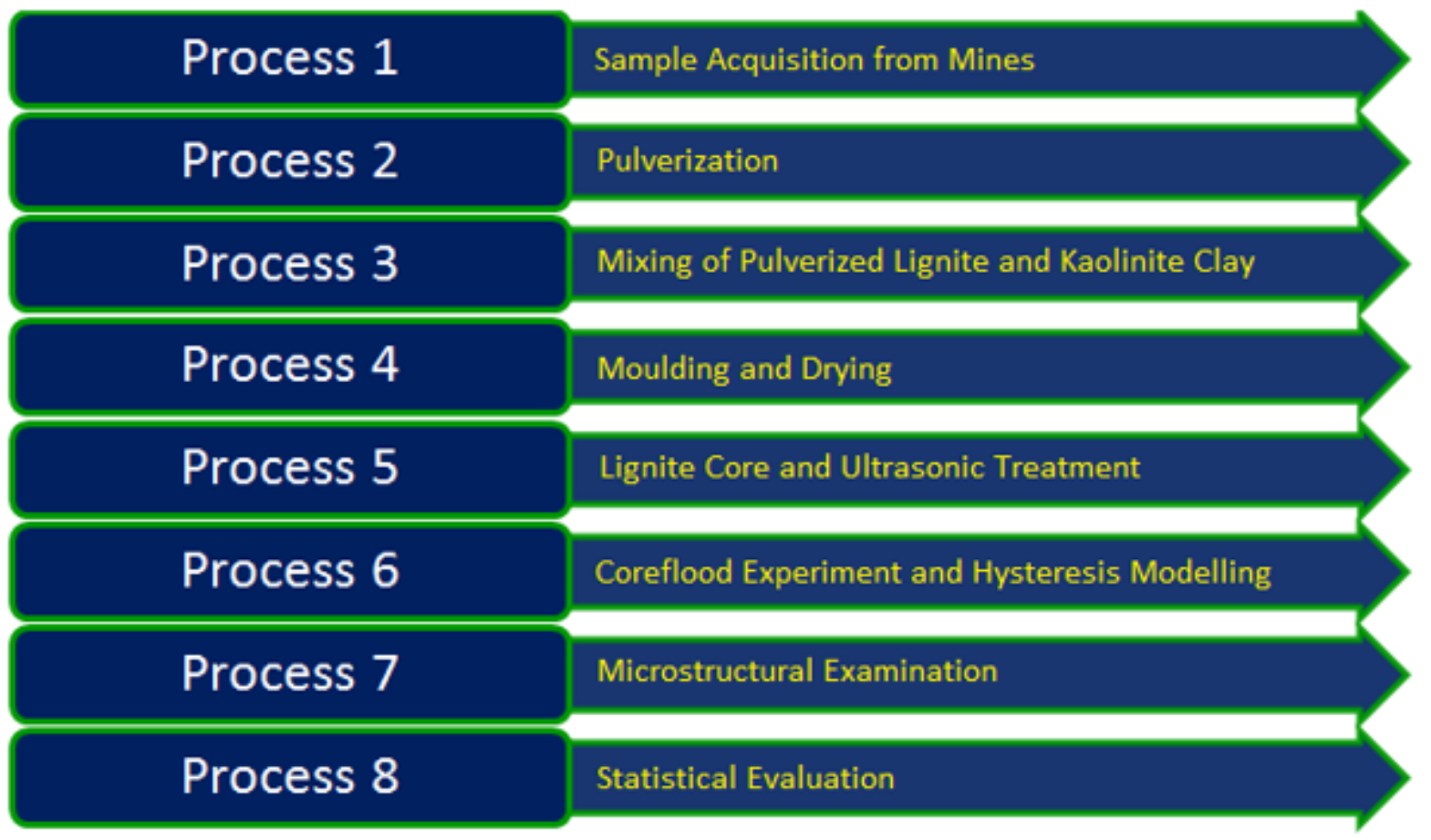

\section{Figure 11}

Research methodology flow chart

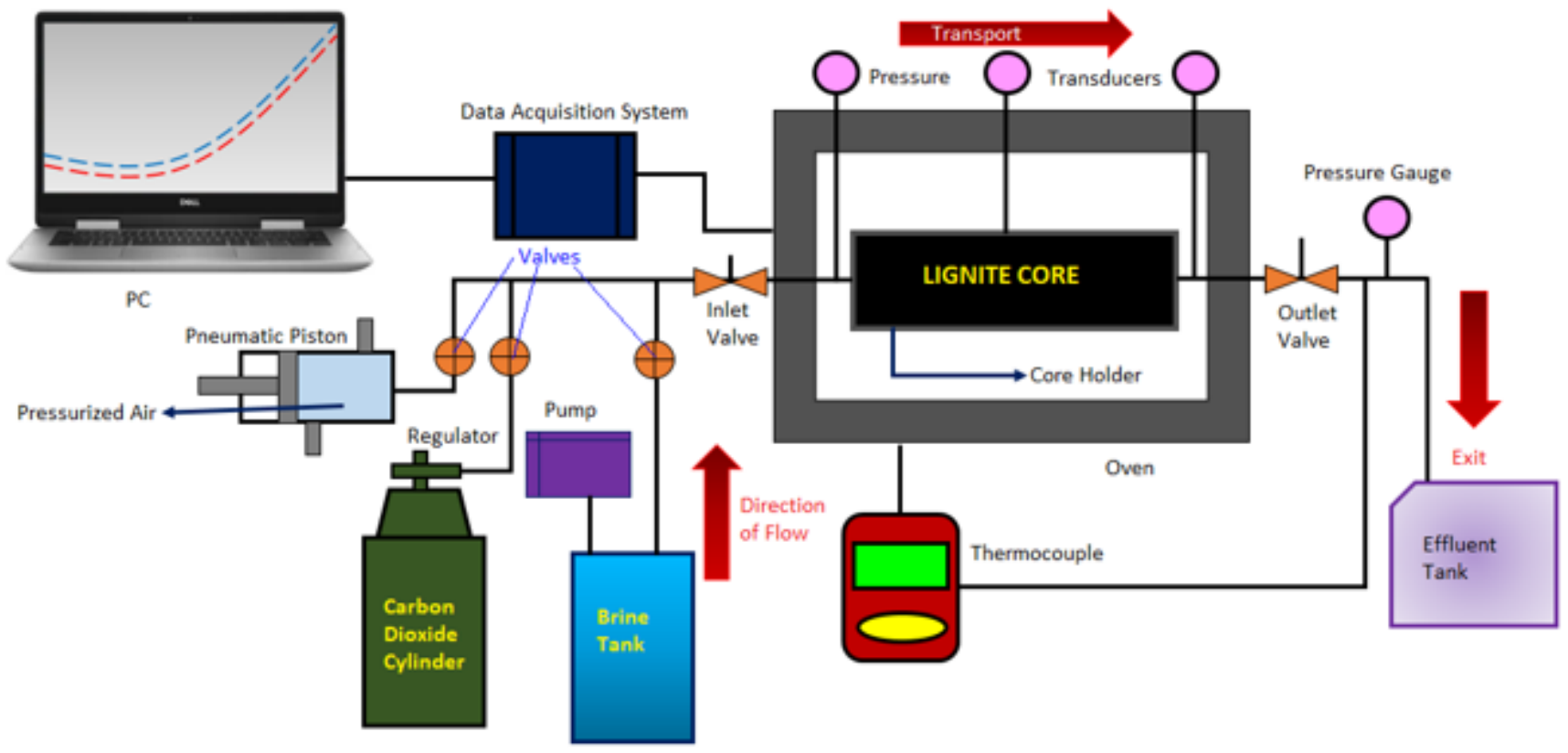

Figure 12

Experimental setup 


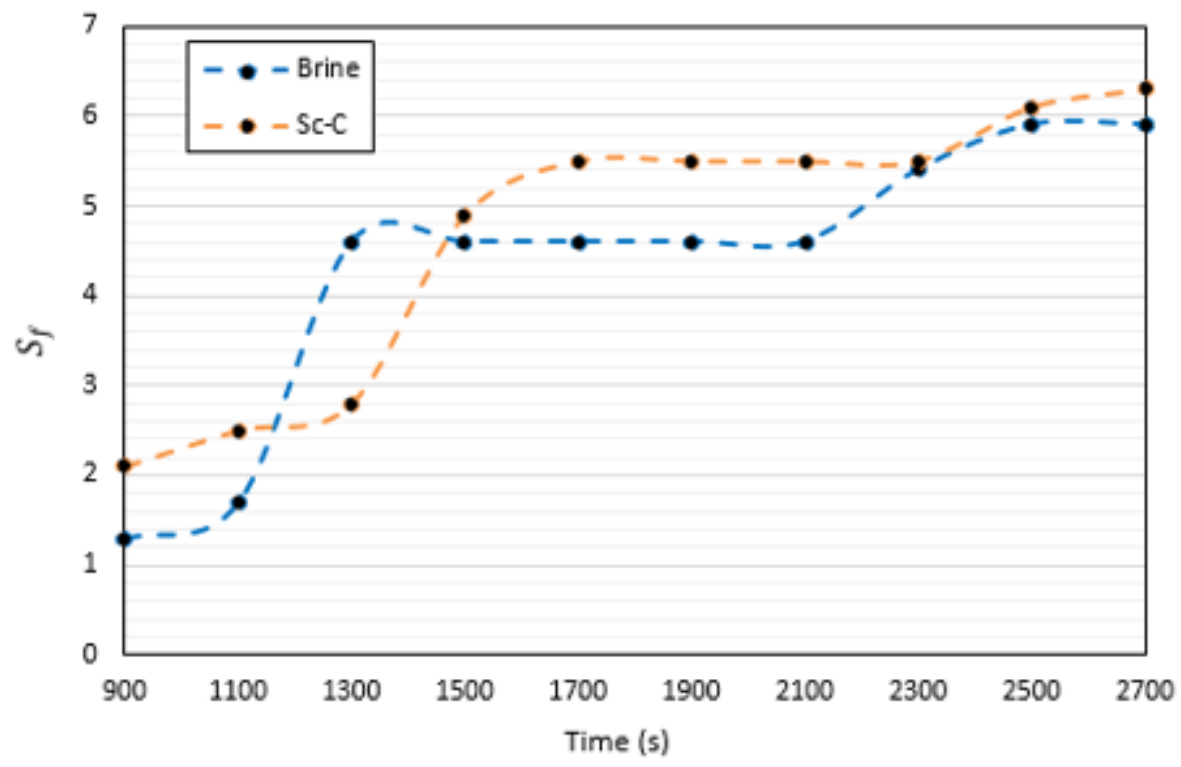

Figure 13

Variation of injected fluid saturation in lignite core with respect to increasing time

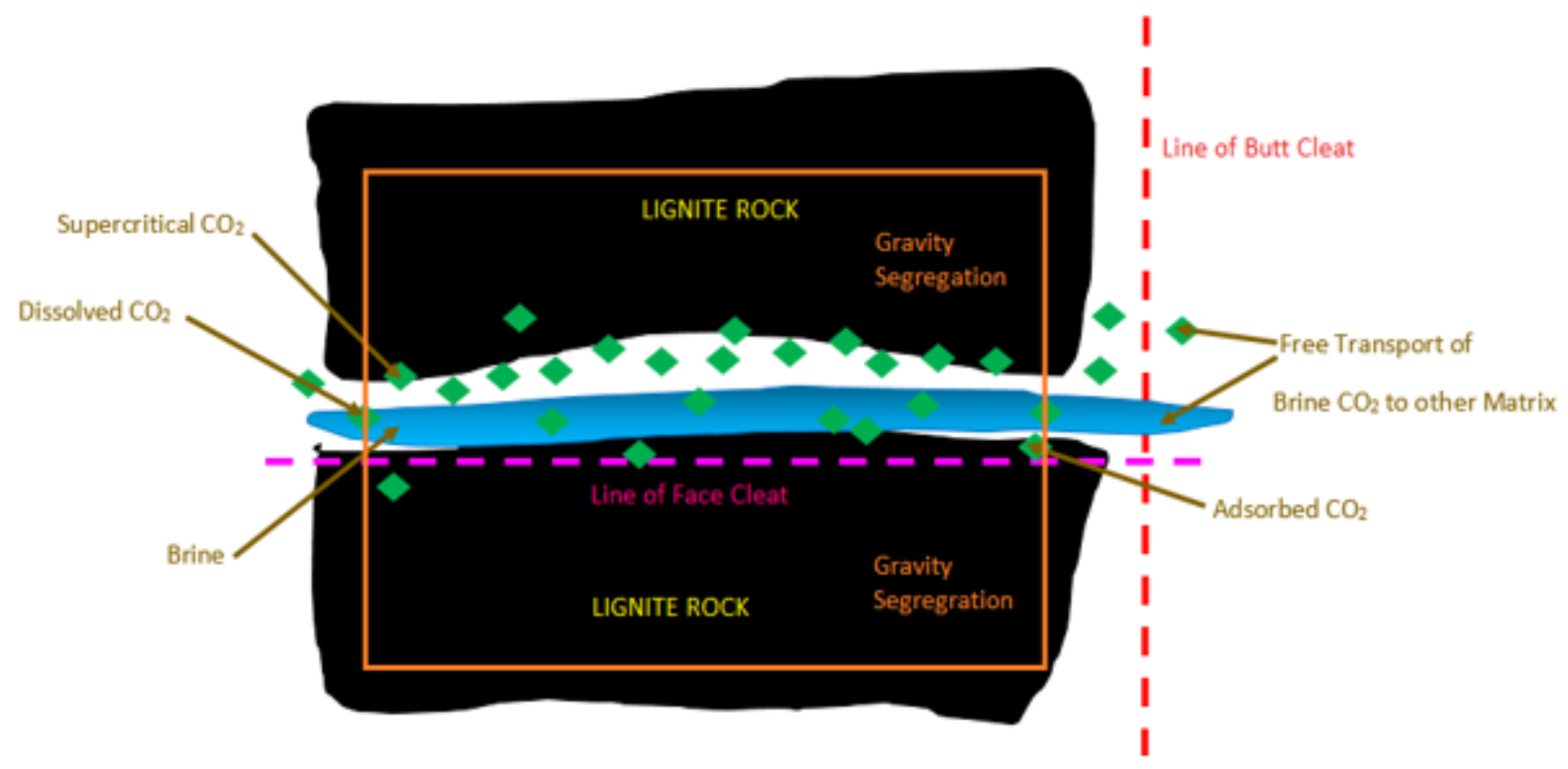

Figure 14

Schematic diagram illustrating gravity segregation in a single lignite rock matrix 


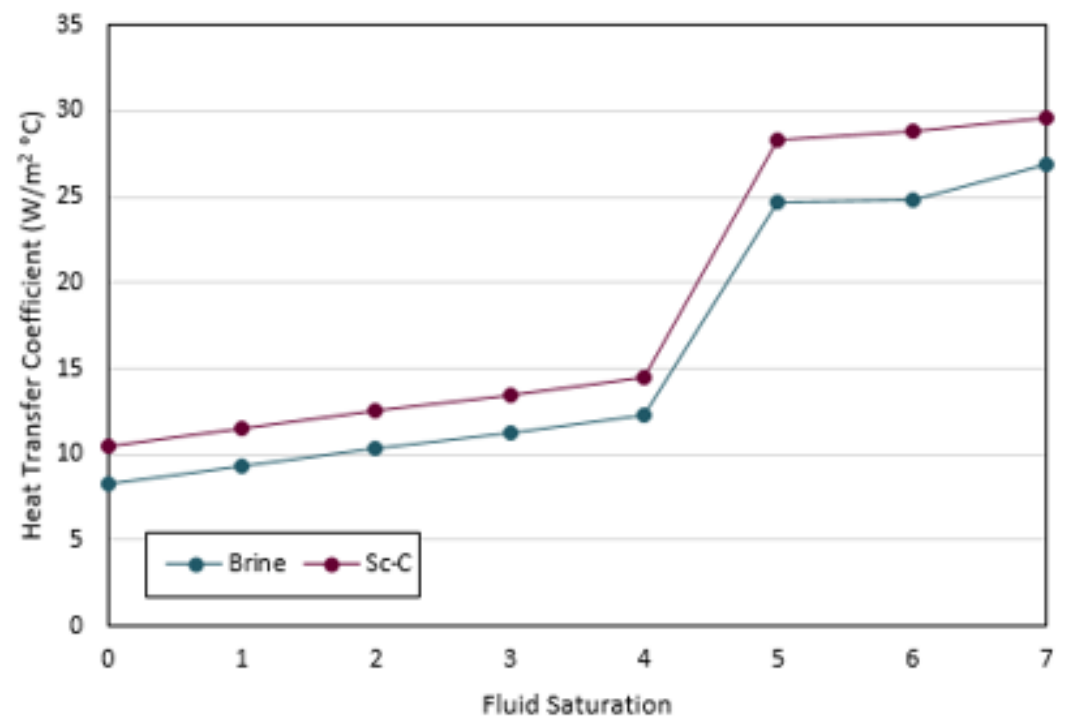

Figure 15

Heat transfer coefficient variation with respect to increasing fluid saturation

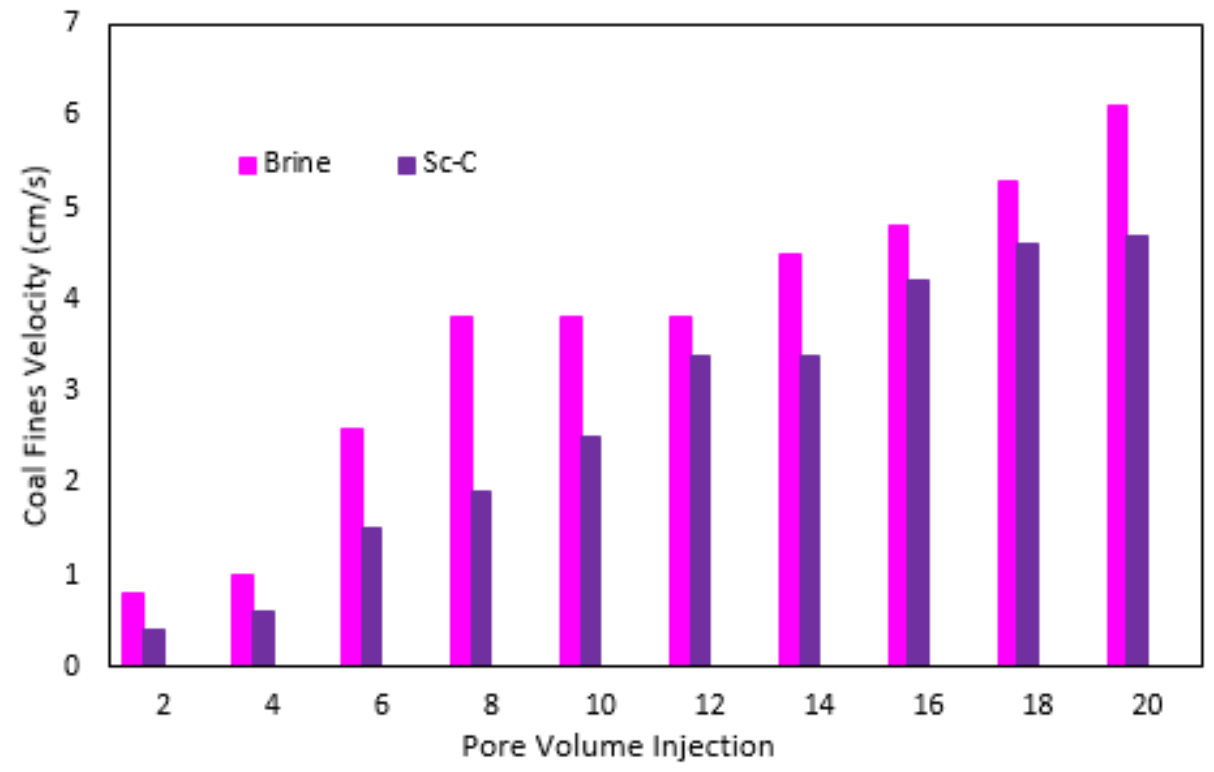

Figure 16

Coal fines velocity variation with respect to increasing PVI 


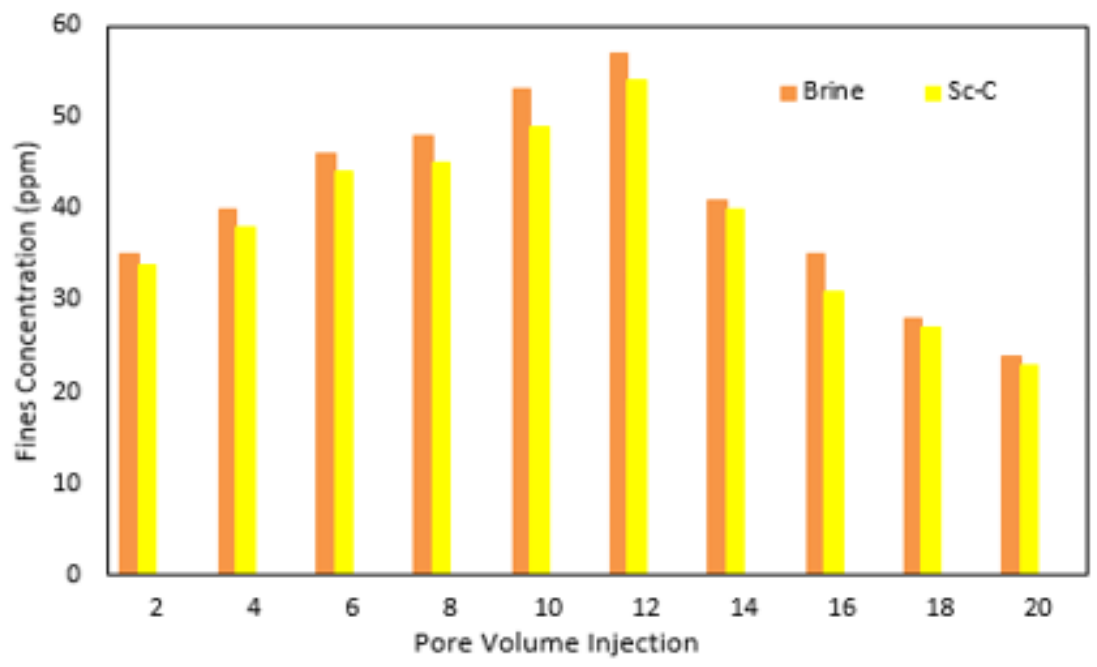

Figure 17

Kaolinite fines concentration variation with respect to increasing PVI

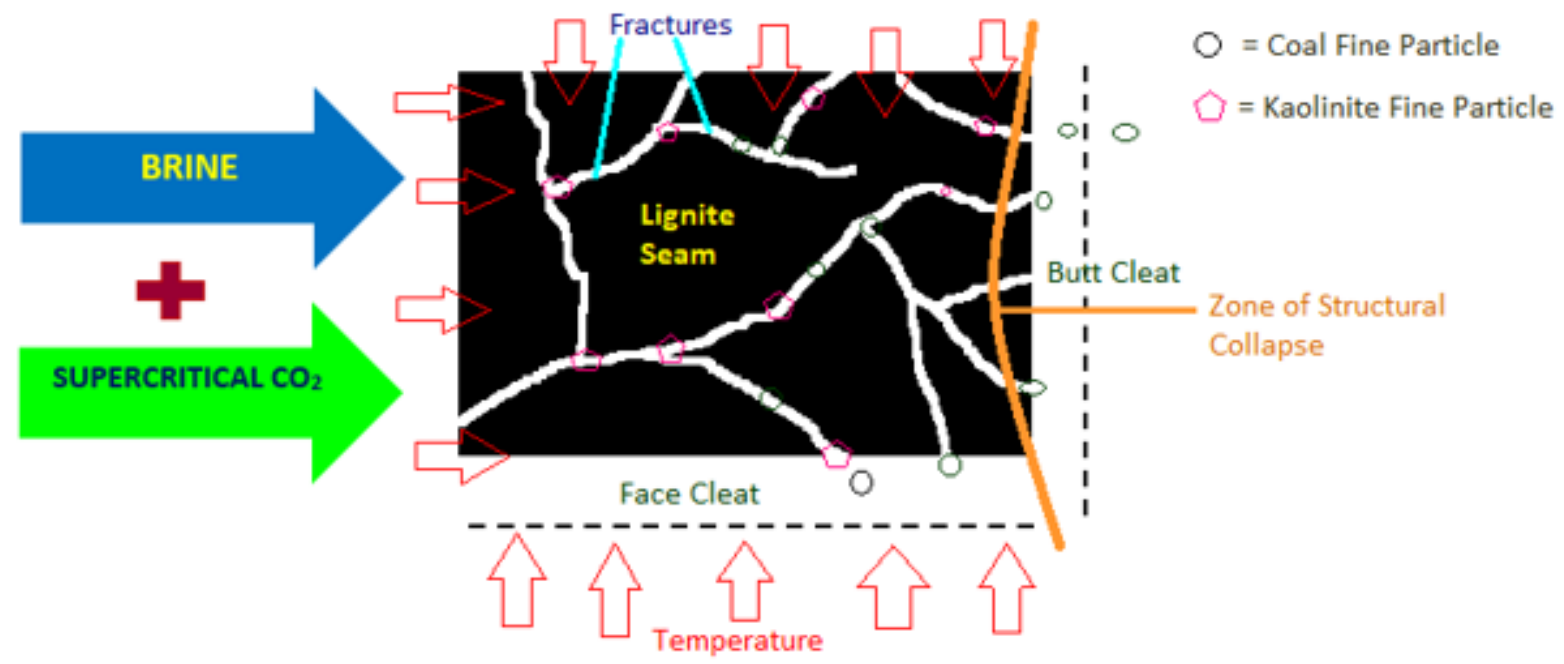

Figure 18

Schematic diagram illustrating fracture generation and coal fines production under WAG injection in a single lignite rock matrix 


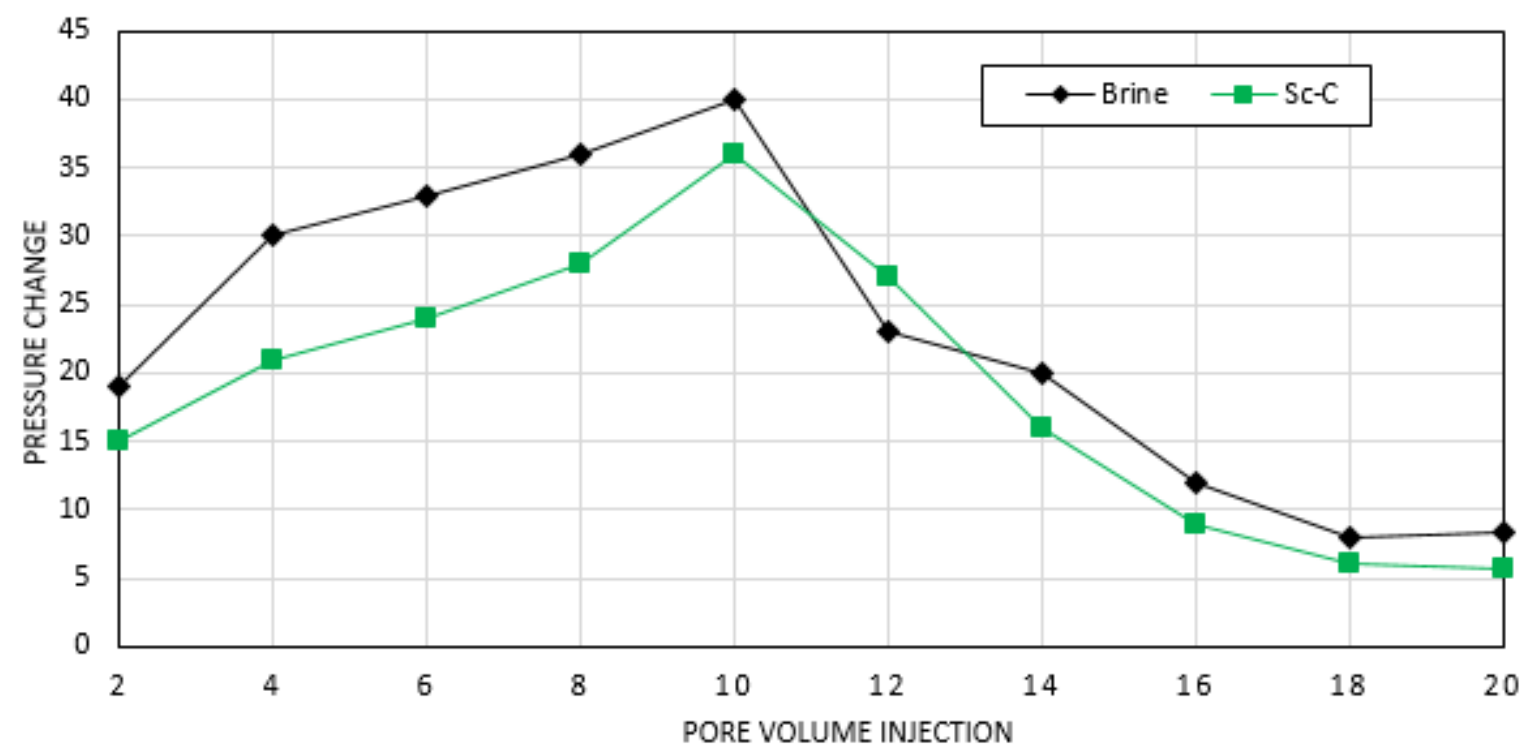

Figure 19

Pressure change with respect to increasing PVI

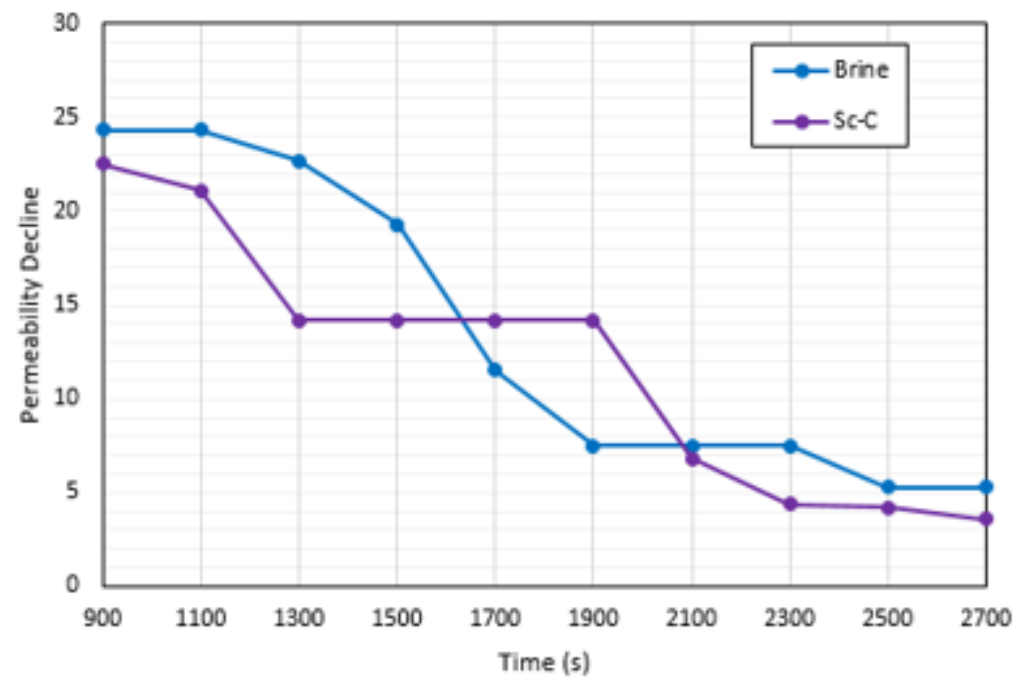

Figure 20

Permeability decline with respect to increasing time 


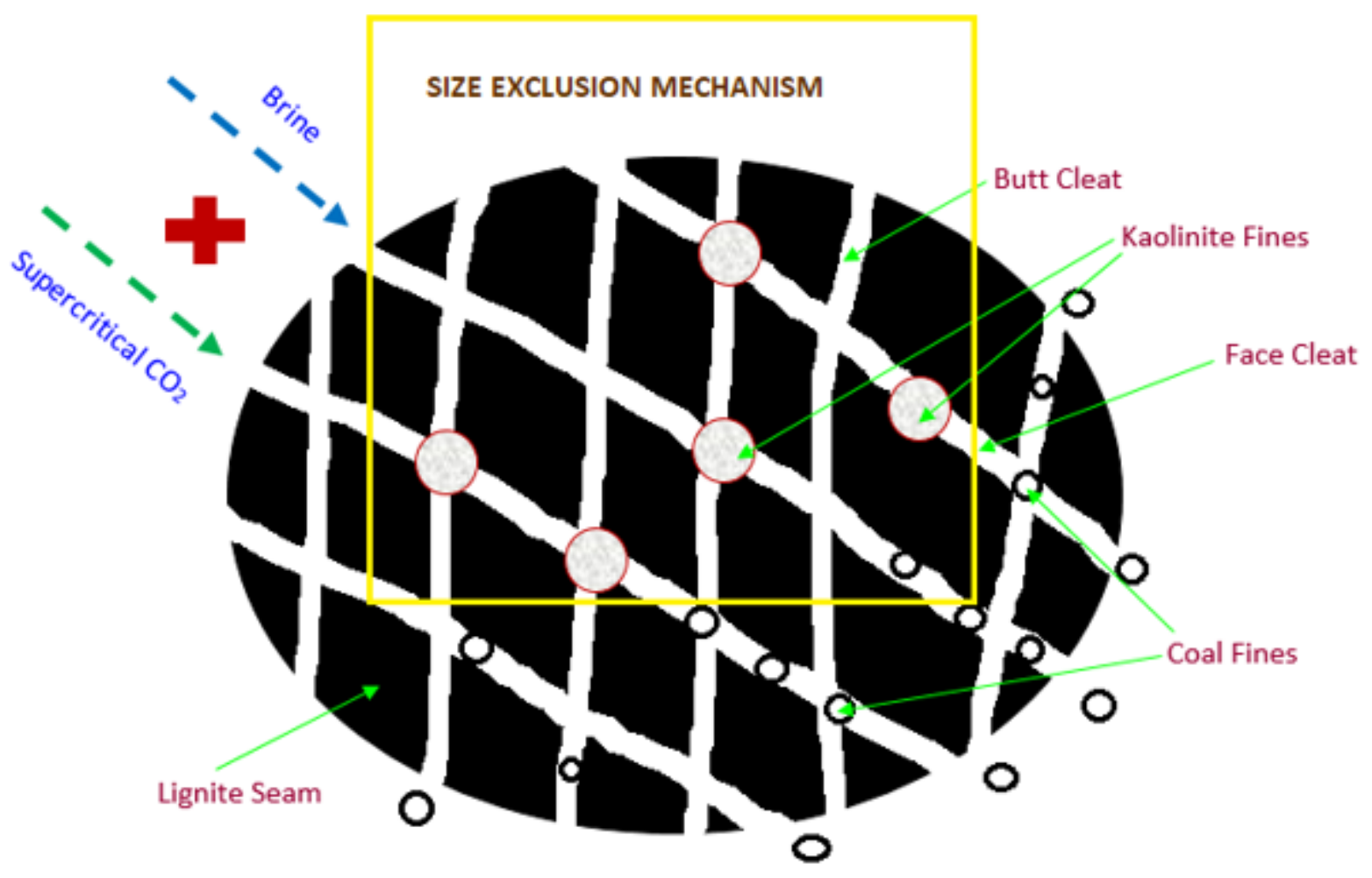

\section{Figure 21}

Schematic two dimensional isometric view of size exclusion mechanism between kaolinite clay fines and cleats in a lignite seam
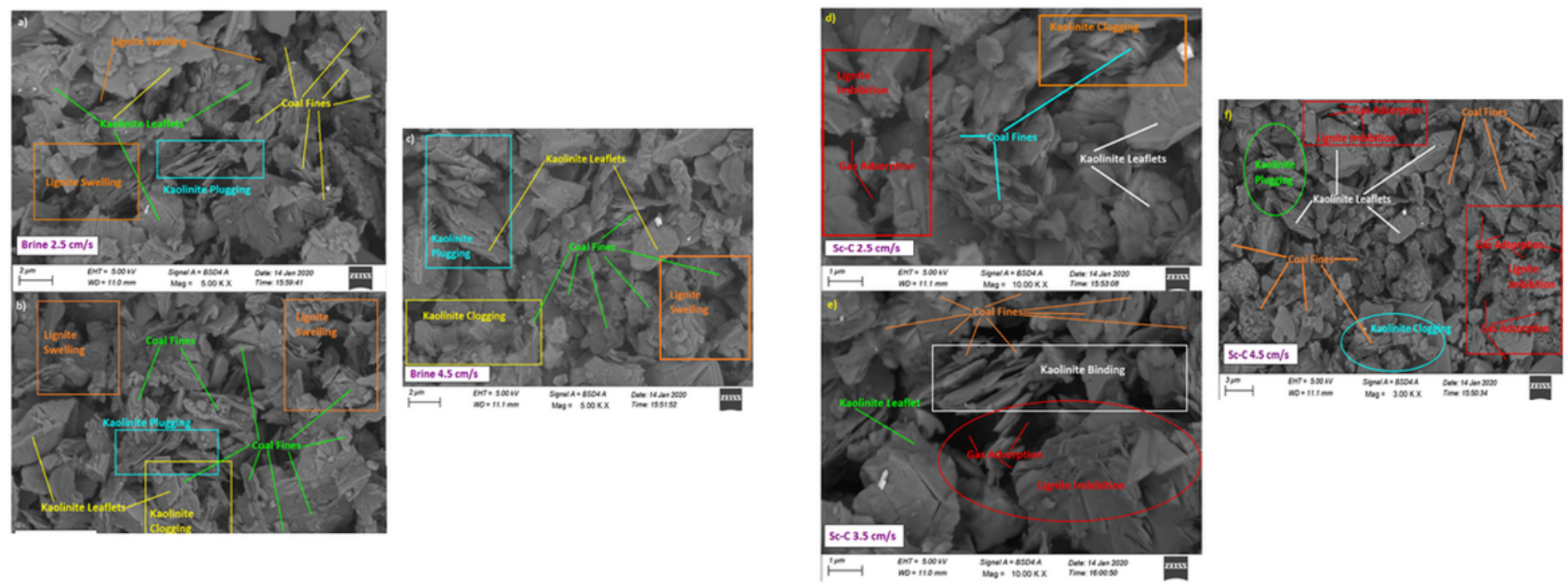

Figure 22

Left: FESEM images of produced suspensions, a) Brine $2.5 \mathrm{~cm} / \mathrm{s} 2 \mu \mathrm{m}, \mathrm{b}$ ) Brine $3.5 \mathrm{~cm} / \mathrm{s} 2 \mu \mathrm{m}, \mathrm{c}$ ) Brine 4.5 $\mathrm{cm} / \mathrm{s} 2 \mu \mathrm{m}$. For enlarged view of all these FESEM images, a reader is advised to see the appendix. Right: 
FESEM images of produced suspensions, d) Sc-C $2.5 \mathrm{~cm} / \mathrm{s} 1 \mu \mathrm{m}$, e) Sc-C $3.5 \mathrm{~cm} / \mathrm{s} 1 \mu \mathrm{m}, \mathrm{f}$ ) Sc-C $4.5 \mathrm{~cm} / \mathrm{s}$ $3 \mu \mathrm{m}$. For enlarged view of all these FESEM images, a reader is advised to see the appendix.

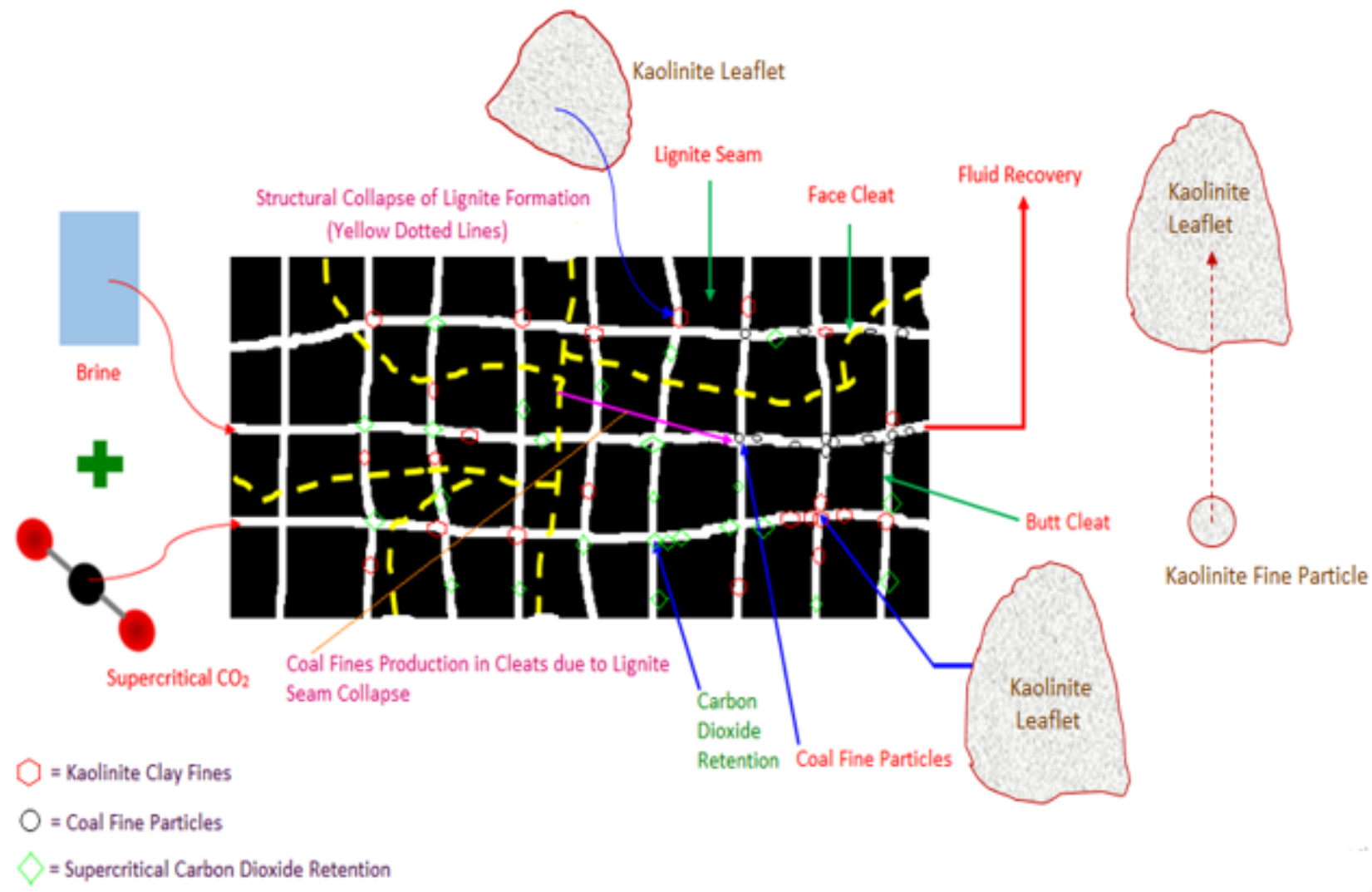

\section{Figure 23}

Plausible mechanism of permeability damage in lignite core due to the intrusion of kaolinite leaflets, coal fines, and CO2 retention under WAG transport
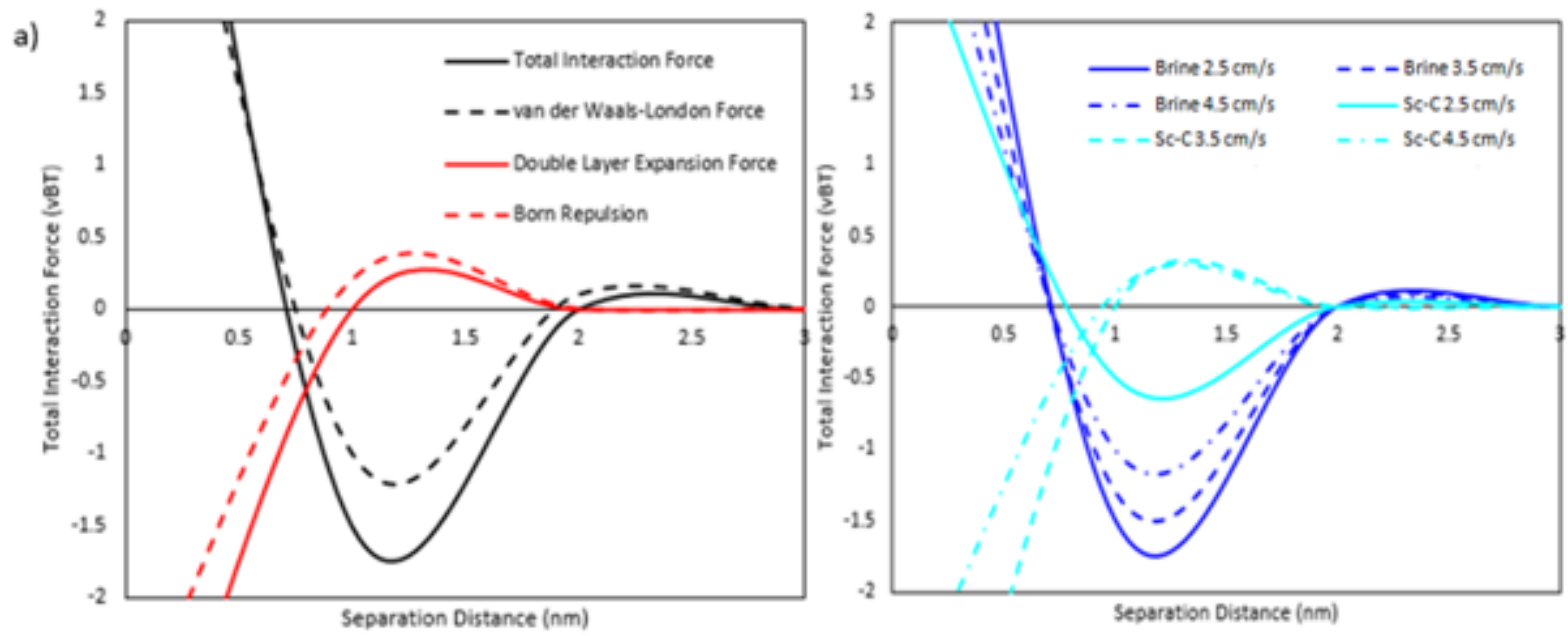

b)

Figure 24 
a) Electrostatic interaction between kaolinite fines and lignite rock under various forces, b) Electrostatic interaction between kaolinite fines and lignite rock under brine and Sc-C flow under different velocities

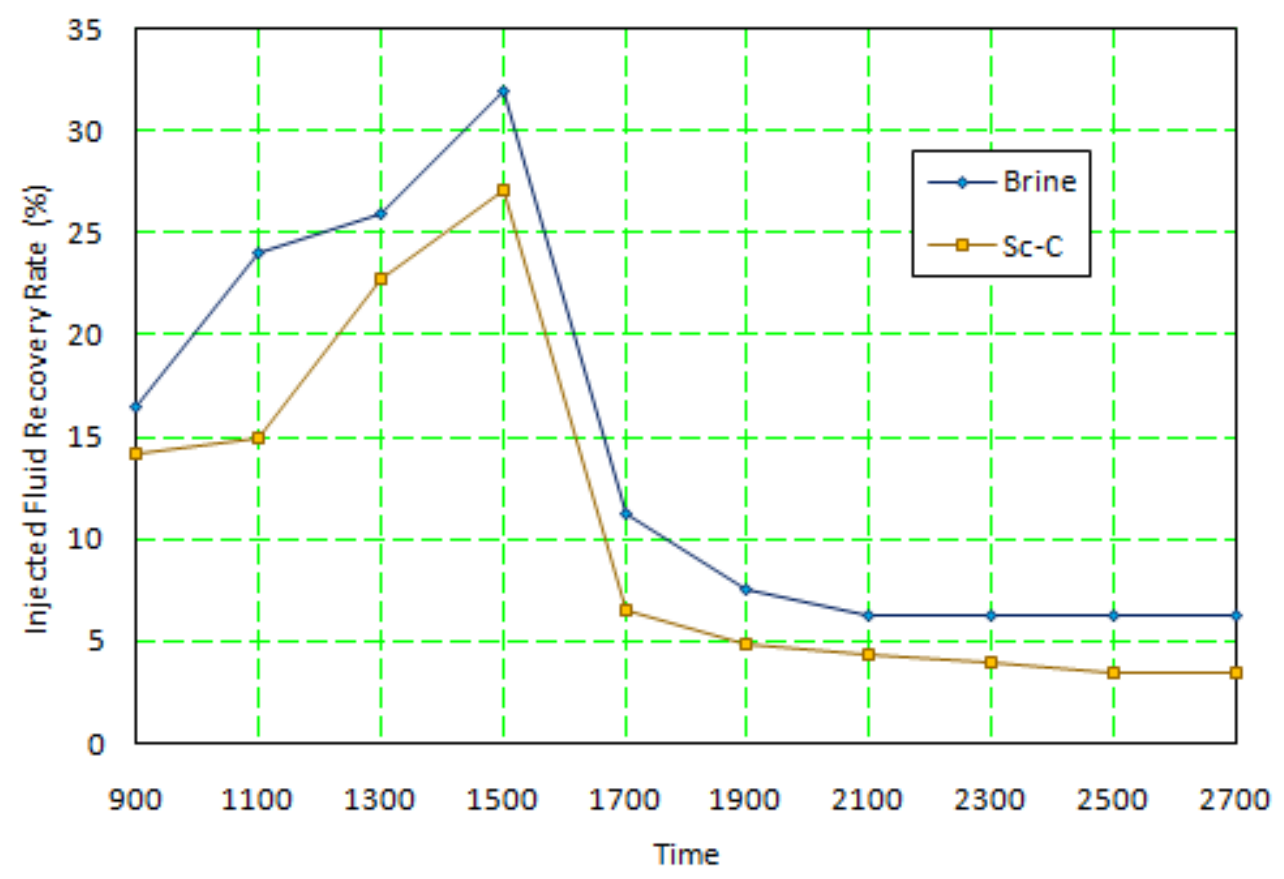

Figure 25

Variation of injected fluid recovery rate with respect to increasing time

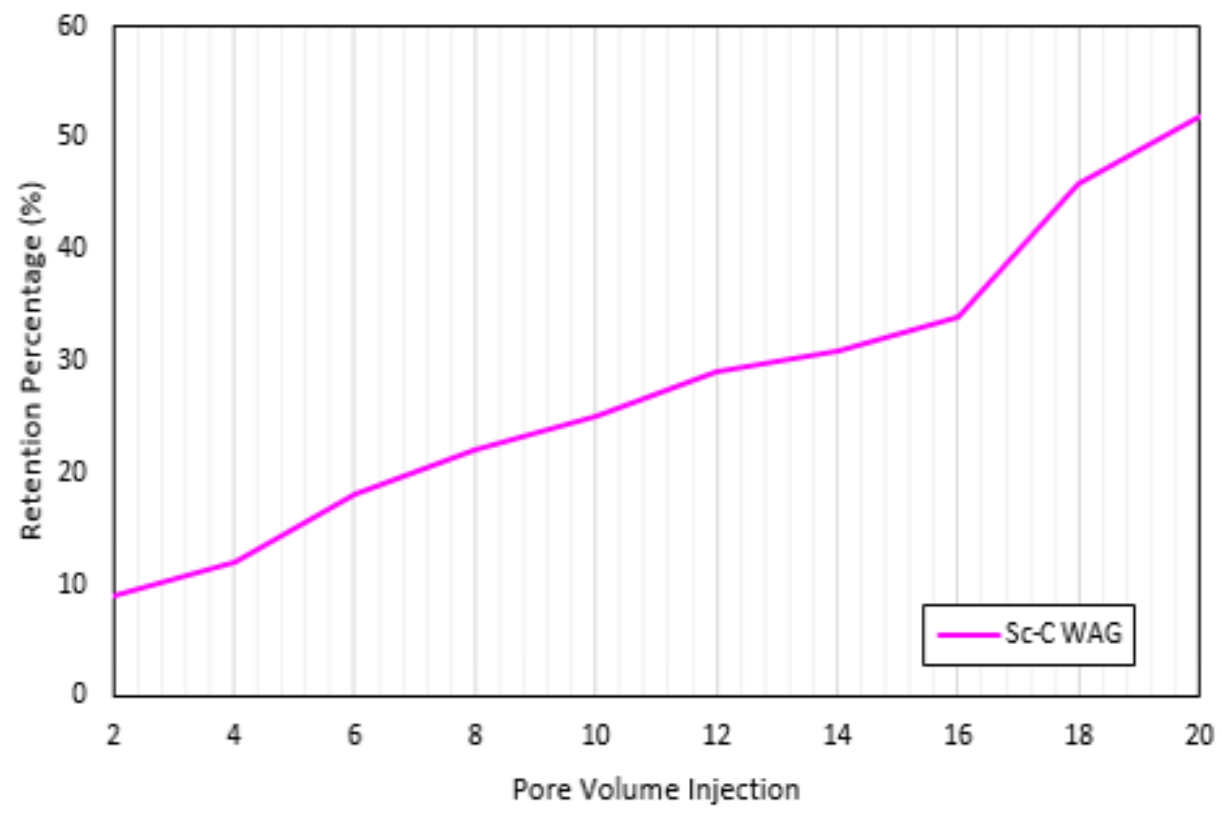

Figure 26

Variation of $\mathrm{CO} 2$ retention percentage with respect to increasing $\mathrm{PVI}$ 

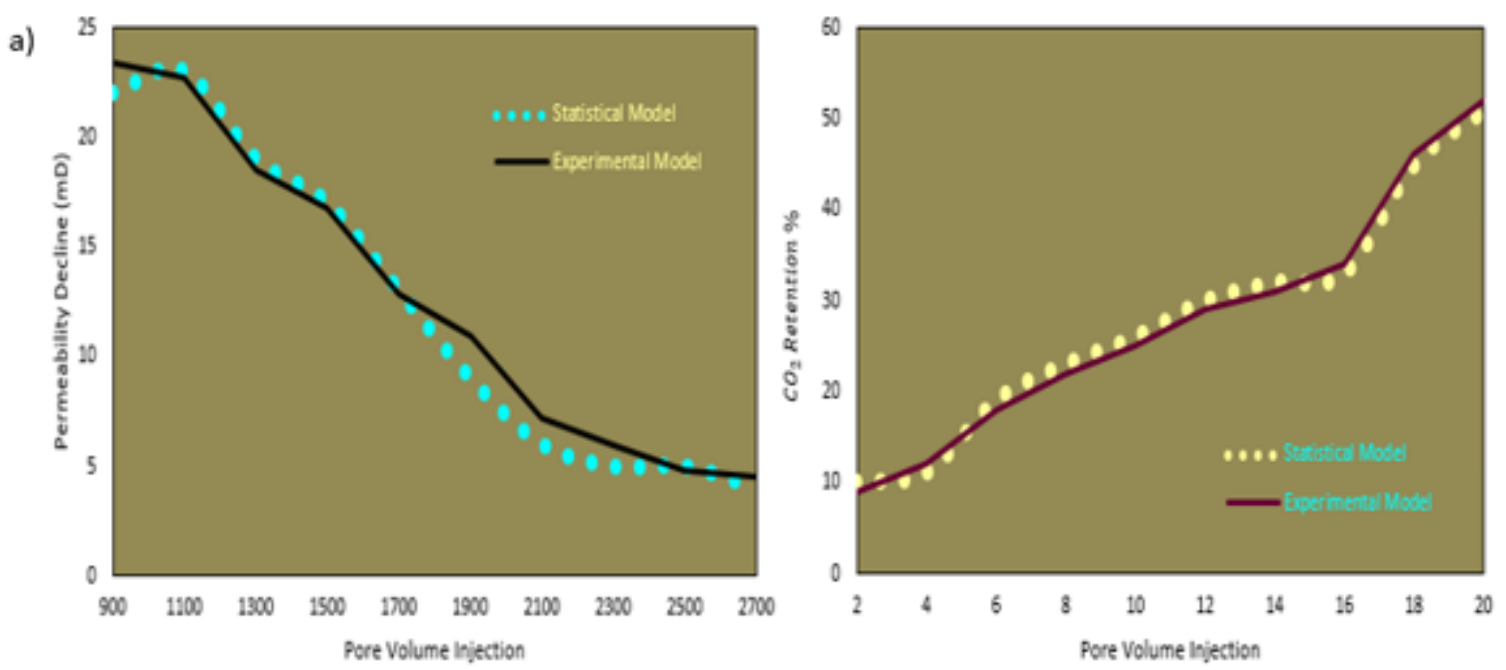

b)

Figure 27

Model validation, a) Permeability decline with respect to increasing PVI, b) $\mathrm{CO} 2$ retention percentage increase with respect to increasing PVI

\section{Supplementary Files}

This is a list of supplementary files associated with this preprint. Click to download.

- CoalCoalSDF.docx 